\title{
The SPQR («Semper Paratus ad Qualitatem et Rationem») Principle in Action
}

\author{
Fausto Galetto ${ }^{1,2}$ \\ ${ }^{1}$ Independent Scholar, Buccinasco (Milan), Italy \\ ${ }^{2}$ Department of Production and Business Economics (Industrial Quality Management), Politecnico di Torino, Turin, Italy \\ Email address: \\ fausto.galetto@gmail.com
}

To cite this article:

Fausto Galetto. The SPQR («Semper Paratus ad Qualitatem et Rationem») Principle in Action. Engineering and Applied Sciences. Vol. 2, No. 3, 2017, pp. 27-52. doi: 10.11648/j.eas.20170203.11

Received: May 25, 2017; Accepted: June 6, 2017; Published: July 13, 2017

\begin{abstract}
We show an application of the SPQR Principle [«Semper Paratus ad Qualitatem et Rationem ("Always Ready for Quality and Rationality")»] as the way to analyse papers and books; it seems that very few people have taken care of Quality of Methods (Deming, Juran, Gell-Mann, Shewhart, Einstein, Galilei). The case analysed here is about a Design of Experiment application to Large-Scale Metrology and to Control Charts.
\end{abstract}

Keywords: Methods Quality, Large-Scale Metrology, Peer Review, Open Access, Rational Manager

\section{Introduction: "The Problem Outline"}

Many researchers use citations of papers and books as index of the Quality of the methods given in those papers and books: according to the author this is a very BAD attitude. On the contrary they should use the correct (Scientific) way to analyse the data and make decisions about the methods suggested.

Another wrong attitude is found in the web: Open Access Journals are criticised because they are "means for tricking people" (asking fees for publishing papers). For example, for Science Publishing Group, they say either [1] "Science Publishing Group is another scam Open Access journal publisher or academic vanity press.... the journals put out by the Science Publishing Group are not read by scientists and have no impact factor." or [2] "They will distribute it globally and pretend it is real research, for a fee. It's untrue? And parts are plagiarized? They're fine with that. Welcome to the world of science scams, a fast-growing business that sucks money out of research, undermines genuine scientific knowledge, and provides fake credentials for the desperate."

In my opinion, the bad quality of the paper published does not depend on the fee, asked by the OA Publishers (OAP), but on the very low quality of the authors and of the Peer Reviewers; the same happens for "well reputed magazines and journals" [see the long bibliography of Fausto Galetto].

Due to that, the author stated the SPQR Principle [«Semper
Paratus ad Qualitatem et Rationem ("Always Ready for Quality and Rationality")»] as the way to analyse papers and books; it seems that very few people have taken care of Quality of Methods. To the author knowledge, they are Deming, Juran, Gell-Mann, Shewhart [3-8]. Fausto Galetto would like to know somebody else who did that... In his last years of life A. Einstein wrote: «An Academic career poses a person in an embarrassing position, asking him to produce a great number of scientific publications; only strong personalities can resist to this seduction toward the superficiality... I am very grateful to Marcel Grossmann if I had the fortune not to be in this hard position.» It is not surprising that professors, researcher, managers, scholars and students learn wrong ideas, in the Quality field, BECAUSE we have a very widespread book with many wrong concepts \{e.g., D. C. Montgomery falls in contradiction! He spreads wrong concept on Quality $[9,10]\}$. Is Wiley \& Sons an OAP?

The Quality Engineering Group (QEG, comprising several professors) suggests the Montgomery books to students; therefore it is not a surprise that the case we analyse here has various problems $[11,12]$. In the web you can find: «"Welcome to the website of the Quality Engineering Group... The research group... deals with research areas related to Quality Engineering. In particular current research interests are in the areas of Statistical Process Control, Service Quality 
Management and Industrial Metrology. The group is working also on Bibliometrics and Performance Indicators. This website was created with the goal of promoting the research activities carried out by the group.»!) Fantastic... See Ref.

QEG members think that Bibliometrics is very important for quality of papers.... See $\S 7$ and the References (Galetto papers)

You can find the drawbacks of Bibliometrics in the F. Galetto paper [97] "Bibliometrics: Help or Hoax for Quality?". (there are some ideas of QEG!!!).

The case we analyse here [32, a QEG book] (Springer-Verlag London is OAP?) is a very interesting application of DOE (Design Of Experiments) to Large-Scale Metrology settings. It is important for our purpose because in this case we do not have the data and then we are in the situation where many times a reader is: the conclusions of the authors are given and the reader must "Take it or leave it", without any possibility of verifying them! It is the same in [33, a QEG paper] (Surely IEEE Trans Instrum Meas is not an OAP)

The wrong documents from 9 to 31 are not published by OAP (Open Access Publishers): the publishers do not ask the fee to the authors, they ask the fee to the readers! As for OAP the Quality of the documents depends on the authors.... You see that in the paper [111] Six Sigma Hoax: The Way Professionals Deceive Science.

In order not to be cheated, the only way left to the reader is to use his own intelligence together with the SPQR Principle...

We mainly use excerpts from the book (published in 2011) and in one of the last papers, I could see (2010) [32, 33].

Reader be SPQR «Semper Paratus ad Qualitatem et Rationem», to understand clearly the issue, remembering Deming's, Gell-Mann ideas and Quality Tetralogy that must be in the mind of every Scholar.... (see figure 1, given in this introduction because it shows the prerequisite of Quality)

The present paper is offered to Managers, to Students (aiming at becoming Future Managers), to Young Researchers (aiming at becoming Scientific Researchers), to Scholars (aiming at learning Scientific ideas), and to Professors who want to learn the BASICS of Decisions based on the Scientific Analysis of problems and solutions in order to make Quality Decisions in their work of practical Research, Theoretical Research and Management.

It aims at showing in some detail the several aspects related to Management of Quality and Problems Solving, because only good methods are crucial for suitable decision taking. Decision-making is something which concerns everybody, both as maker of the decision (after either a serious or non-serious analysis) and as sufferer of the decision of other people (as well, after either a serious or non-serious analysis by them). Often we need data to decide: we analyse them to decide and we must take into account the consequences of our decisions; unfortunately always the data are affected by variability (they are uncertain to us) and therefore we need to consider uncertainties in detail and introduce them into the analysis for "decision-making under uncertainty".
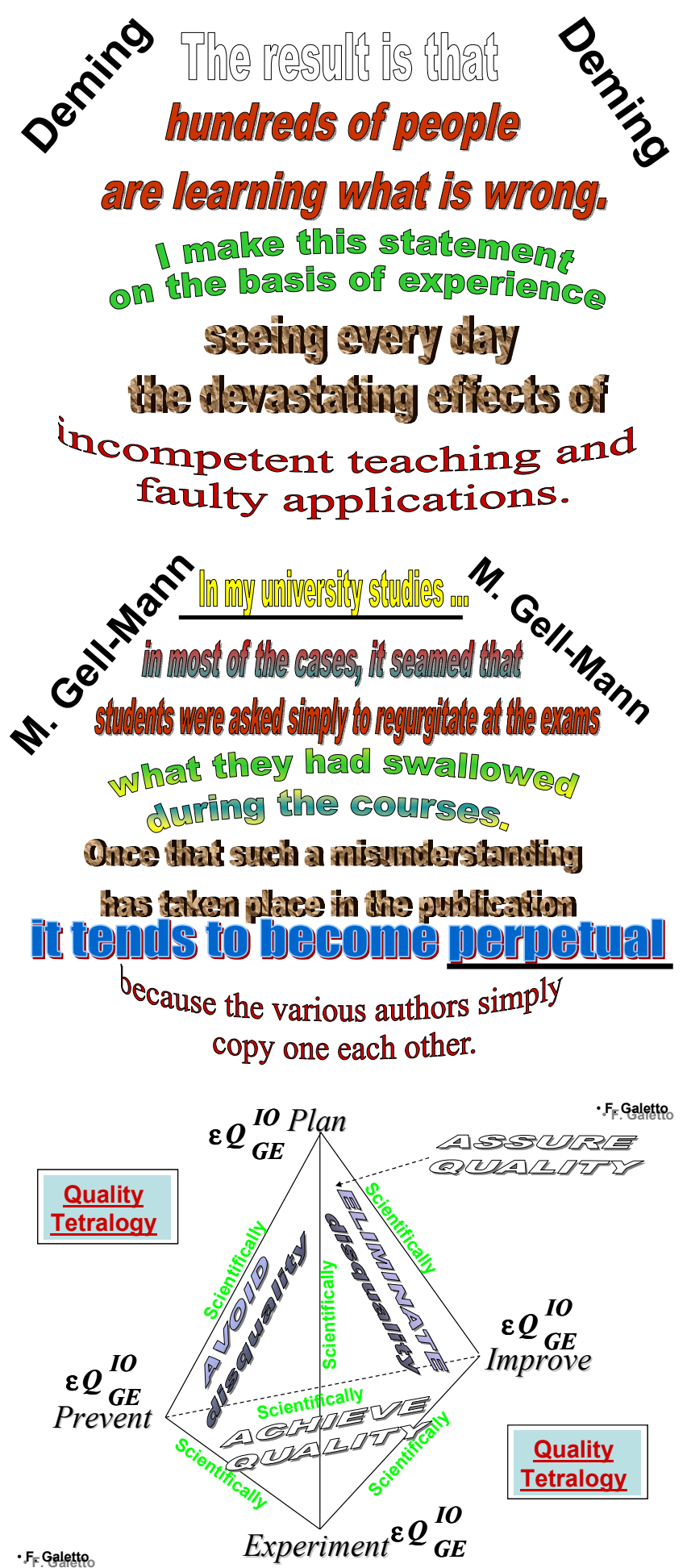

Figure 1. Statements from Deming, Gell-Mann, Galetto ideas.

The worst thing a reader may encounter is when he does not have the data to analyse: this is the case here!

The two figures 2 and 3 (the $1^{\text {st }}$ an Excerpt, and the $2^{\text {nd }}$ of Fausto Galetto) are given to let the reader see the experimental setting for the Distributed Large-Scale Dimensional Metrology.

There is a frame like a parallelepipedon; at the bottom there is the item to be measured, the measurand; on the top face, the ceiling, there is a set of the transceivers (optimised in position 
and number) that receive and send UltraSound (US) signals with a probe; the US signals take a certain time, the TOF (Time Of Flight), used to measure the measurand.

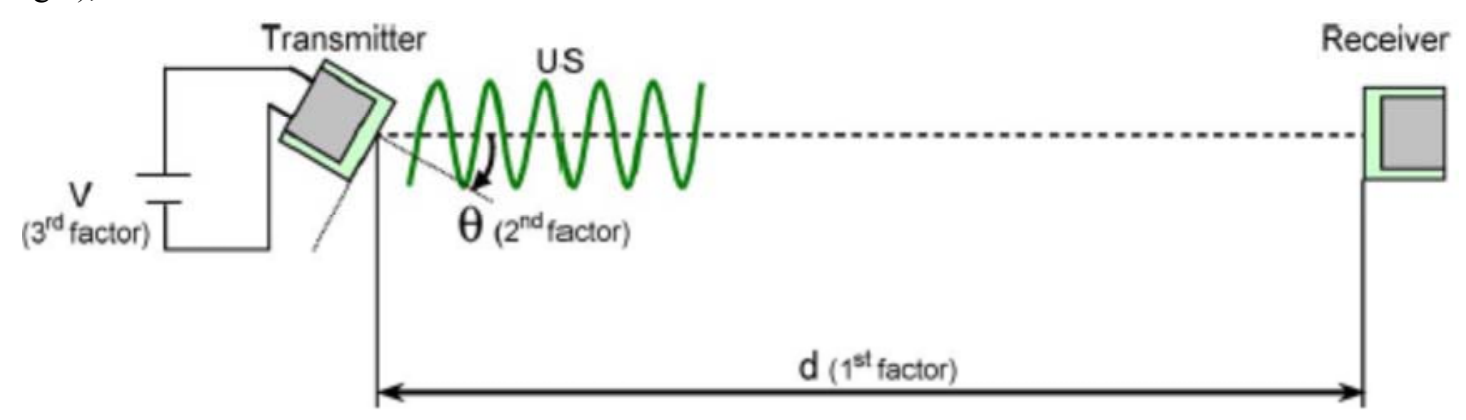

Figure 2. Excerpt (from the paper [33]).

the 3 factors are

$\mathrm{d}$ : the horizontal distance between the network devices $\left(\mathrm{C}_{1}, \ldots, \mathrm{C}_{\mathrm{n}}\right)$ and the probe (crickets)

$\theta$ : the angle (misalignment angles) between the normal vector of network devices $\left(\mathrm{C}_{1}, \ldots, \mathrm{C}_{\mathrm{n}}\right)$ and the probe (crickets)

$\mathrm{V}$ : the battery charge of the crickets (on the probe)

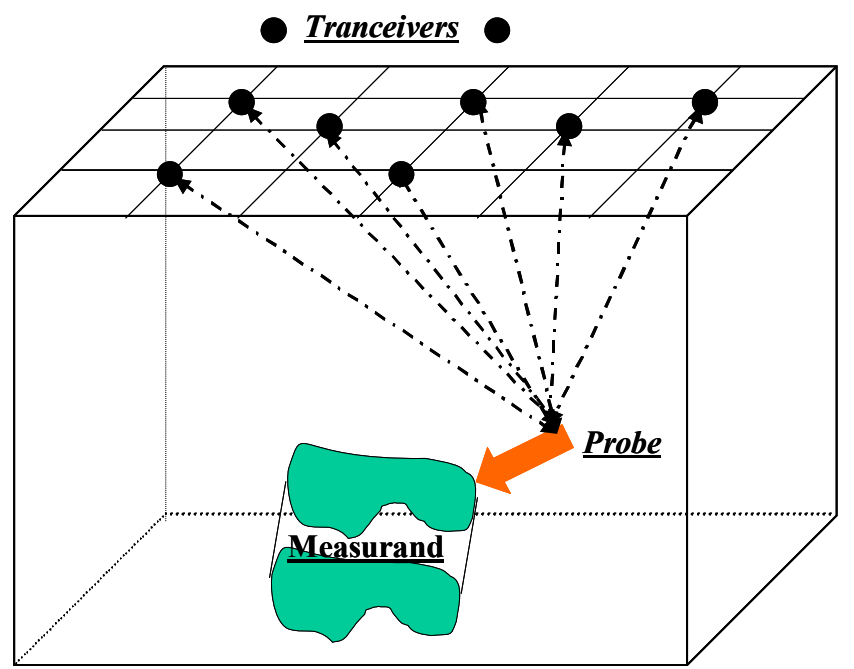

Figure 3. The experimental layout.

In the figure 3 you see

a. a network (or "constellation") of sensing devices, distributed within the working volume;

b. a portable probe to "touch" the points of interest on the surface of the measured object ("measurand"), so as to obtain their spatial coordinates;

In the book [32] (2011) the $3^{\text {rd }}$ factor (V) is not considered. The purpose of the book [32] is given in the Foreword: " $A$ detailed description of operating principles, and performance characteristics, is presented, along with a thorough treatment of such key aspects as system calibration, self-diagnostics and evaluation of measurement uncertainty. Besides state of art description, practical guidance to users is provided, a most welcome feature for operators involved in actual operation. We wish to congratulate the authors for sharing with all those concerned their outstanding experience, and packing so much valuable information in this book." (R. Levi, Professor
In the paper [33] (2010) one finds the following figure where one sees the 3 factors used in the DOE;
Emeritus at the Fourth School of Engineering of Politecnico di Torino, Italy S. Rossetto, Dean of the Fourth School of Engineering of Politecnico di Torino, Italy) [both appreciated the Montgomery book..., as done by the $Q E G$ members, who teach the following formula (with wrong attached statement)

$$
\sigma_{\bar{x}}=\frac{\sigma}{\sqrt{n}} \quad \text { (from statistics: central limit theorem) }
$$

!!!] QEG fellows suggest Montgomery books to students [!!!] BUT they do not know that the previous formula DOES NOT depend on the Central Limit Theorem!!!!!!! (as any good student knows!!!).

\section{The Experiments Carried out, First Part}

In their book [32], at § 7.2.2 Description of the Experiments, one finds the experiments carried out for constructing the correction model. Network devices were assumed to be parallel with respect to the devices to be localized. In the current practice, this condition is generally satisfied because network devices $\left(C_{1}, \ldots, C_{n}\right)$ are arranged on the ceiling, at the top of the measuring area and Crickets to be localized are generally mounted on the portable probe and oriented upwards. This configuration is a practical solution to obtain a good coverage and to maximize the measuring volume.

In this configuration, the misalignment angles related to a generic network device $\left(\mathrm{C}_{\mathrm{i}}\right)$ and the one related to the device(s) to be localized, with respect to their distance:

a. transmitter $(\mathrm{T})$ and receiver $(\mathrm{R})$ are positioned facing each other;

b. the distance (d) between transceivers is known and represents the $1^{\text {st }}$ factor of the factorial plan;

c. transmitter face is parallel with receiver face, but they are not perpendicular with respect to the direction of the distance. A misalignment angle $(\theta)$ is introduced and represents the $2^{\text {nd }}$ factor of the factorial plan.

The reference point for determining the transceivers' distance and misalignment angle corresponds to the centre of each US (Ultra Sound) transceiver. 


\begin{tabular}{|c|c|c|c|c|c|}
\hline & \multicolumn{5}{|c|}{$\theta\left(^{\circ}\right)$} \\
\hline & $\overline{0}$ & 15 & 30 & 45 & 60 \\
\hline \multicolumn{6}{|c|}{$\overline{d(\mathrm{~mm})}$} \\
\hline 500 & $v$ & $\checkmark$ & $v$ & $v$ & $\checkmark$ \\
\hline 1,000 & $\checkmark$ & $\checkmark$ & $\checkmark$ & $\checkmark$ & $\checkmark$ \\
\hline 1,500 & $v$ & $\checkmark$ & $\checkmark$ & $\checkmark$ & $\checkmark$ \\
\hline 2,000 & $v$ & $\checkmark$ & $\checkmark$ & $\checkmark$ & $x$ \\
\hline 2,500 & $v$ & $\checkmark$ & $\checkmark$ & $v$ & $x$ \\
\hline 3,000 & $v$ & $\checkmark$ & $\checkmark$ & $\checkmark$ & $x$ \\
\hline 3,500 & $\checkmark$ & $\checkmark$ & $\checkmark$ & $\checkmark$ & $x$ \\
\hline 4,000 & $v$ & $\checkmark$ & $\checkmark$ & $x$ & $x$ \\
\hline 4,500 & $v$ & $\checkmark$ & $\checkmark$ & $x$ & $x$ \\
\hline
\end{tabular}

For some particular combinations of the two factors, transceivers are not able to communicate and, consequently, the experimental table cannot be completely filled. To be precise, measurements can be performed only for 37 of $45(9 \times 5)$ combinations. When the two factors have both large values - i.e., when $\theta=45^{\circ}$ and $d>3,500 \mathrm{~mm}$, and when $\theta=60^{\circ}$ and $d>1,500 \mathrm{~mm}$-measurements are not feasible

$\checkmark$ measurement performed

$\times$ measurement not feasible

Figure 4. Excerpt from the book [32].

Experiments were organized, by QEG, in two steps:

A. Exploratory experiments. Based on a limited number of observations, this phase was aimed at investigating whether the two factors of interest have significant effects on the TOF measurements. [3 levels: $1000 \mathrm{~mm}, 2000 \mathrm{~mm}, 3000 \mathrm{~mm}$ ] and [4 levels: $0^{\circ}, 15^{\circ}, 30^{\circ}, 45^{\circ}$ ] the factor level combinations: all the possible 12 different combinations are carried out in random order and replicated 3 times; consequently, the total number of combinations is 36 . For each combination, TOF measurements are repeated 50 times.

$B$. Detailed experiments. The factor working domain and the number of observations are increased so as to build an empirical regressive model representing the effects of the two factors. [9 levels: $500 \mathrm{~mm}, 1000 \mathrm{~mm}, 1500 \mathrm{~mm}, 2000 \mathrm{~mm}$, $2500 \mathrm{~mm}, 3000 \mathrm{~mm}, 3500 \mathrm{~mm}, 4000 \mathrm{~mm}, 4500 \mathrm{~mm}$,] and [5 levels: $0^{\circ}, 15^{\circ}, 30^{\circ}, 45^{\circ}, 60^{\circ}$; $Q E G$ says [falsely]: All the possible $9 \times 5=45$ different combinations are carried out in random order For each combination, TOF measurements are repeated 50 times.

Actually later $Q E G$ says something different, 37 experiments... (see the excerpt, in figure 4!).

The response variable [the output variable in the RSM (Response Surface Method) context] considered in the factorial plan is the $\mathrm{TOF}_{\text {Error, defined as follows }}$ $\mathrm{TOF}_{\text {Error }}=\mathrm{TOF}_{\text {Expected }}$-TOF, being TOF the Time Of Flight measured by pair of Crickets and $\mathrm{TOF}_{\text {Expected }}=\mathrm{d} / \mathrm{s}$, where $\mathrm{d}$ is the known distance between transceivers and $\mathrm{s}$ is the speed of sound in the experimental conditions (with air temperature $\mathrm{T}=21^{\circ} \mathrm{C}$ and relative humidity $\mathrm{RH}=27 \%, \mathrm{~s} \approx 344 \mathrm{~m} / \mathrm{s}$ )

Let's consider the QEG Results of the Exploratory Experiments and Factorial Analysis (\$7.2.3.1) QEG says:

"Analysing the output of the exploratory factorial experiments, it can be noticed that TOF Error dispersion changes depending on the average of the TOF $F_{\text {Error }}$ value.... In general, the larger the average TOF Error value, the larger the individual measurement dispersion. The non-homogeneity of the TOF Error variance is also tested through the Levene's statistical test, at $p<0.05$. Since the assumption of homogeneity of TOF $F_{\text {Error }}$ variances is violated, the Analysis of Variance (ANOVA) cannot be properly applied, in order to verify whether factors $(d, \theta)$ have a significant effect on the response $\left(T O F_{\text {Error }}\right)$. The usual approach to dealing with non-homogeneous variance is to apply a variance-stabilizing transformation. In this approach, the conclusions of the analysis of variance will apply to the transformed populations. The most common transformation is the exponential $y^{*}=y^{\lambda}$, where $\lambda$ is the parameter of the transformation (the parameter $\lambda$ is selected by the Box-Cox method). The experimenter can analyse the data using $y^{*}$ as the transformed response (hereafter, it will be identified as 'Transformed TOF Error"). In our specific case, the obtained transformation parameter is $\lambda=0.17$. Applying the Levene's test to the transformed response, the resulting variance no longer violates the test's null hypothesis of homogeneity. To construct a model in terms of the original response, the opposite change of variable is performed."

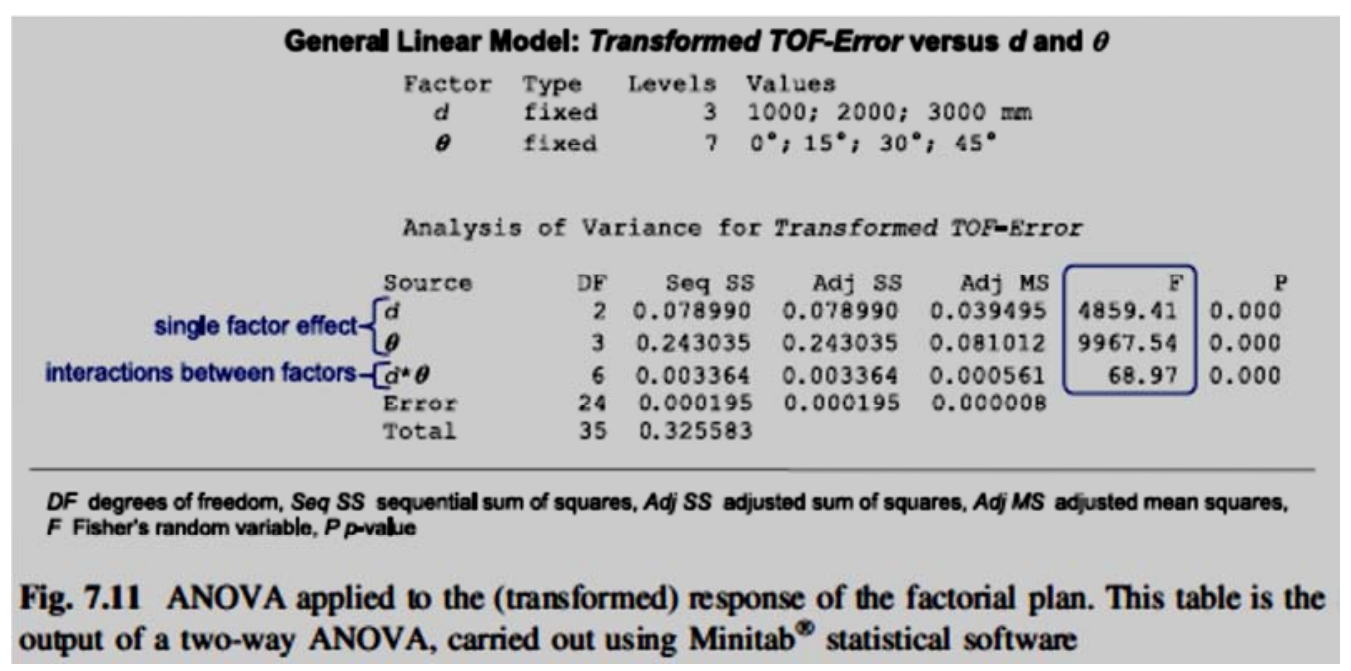

Figure 5. Excerpt from the book [32, where it is given as Figure. 7.11] (Exploratory experiments). 
Since we do not have the data we can only analyse Logically the output of Minitab statistical software!

QEG figure 7.11 (on the top of the figure) [Figure 5, in this paper] shows 7 (why???) levels for $\theta$ !!! On the contrary the degrees of freedom of $\theta$ are 3 , which means only 4 levels. This is confirmed by the df of the interaction $d^{*} \theta$ in QEG figure $7.11, \ldots$.

QEG figure 7.11 shows a "Total DF=35"!!! [3 (levels of d) * 4 (levels of $\theta$ ) * 3 (replications)-1!!!] They used only the means of the 50 data, collected for each treatment combination!!!

QEG transformed the data with $\lambda=0.17$; did they transformed the data or only the means?

They do not tell us!

QEG goes on with

"'"Results of the factorial plan are examined by Analysis of Variance (ANOVA) (see Figure 7.11 [Figure 5, in this paper]). In the ANOVA, the variance related to the response is partitioned into contributions due to the different factors and their interactions. Results of an ANOVA can be considered reliable as long as the following assumptions are met: (1) response variable is normally distributed, (2) data are independent, and (3) variances of populations are equal. After applying the Box-Cox response transformation, all these assumptions were satisfied. In particular, the assumption of normal distribution was verified by the Anderson-Darling normality test at $p<0.05$.

Analysing the ANOVA results, all two factors and their two-way interactions [notice the plural!] were found to be significant based on Fisher's test at $p<0.05$. With regard to single factors, both $d$ and $\theta$ have an important effect. With regard to the factor interaction, it is statistically significant too $(p<0.05)$. Thus, it can be stated that the composition of large misalignment angles $(\theta)$ and large distances (d) produces TOF Errors, which are larger than those obtained adding the effects of the single factors, taken separately."'"

\section{Variance-Stabilizing Transformation}

Now we provide the ideas related to the VST (Variance-Stabilizing Transformation) and we see that the QEG statement ««... exponential $\mathrm{y}^{*}=\mathrm{y}^{\lambda}$, where $\lambda$ is the parameter of the transformation.. optimization method for determining the transformation parameter»»" is FALSE because the Maximum Likelihood method is used, which is NOT an optimisation method!!!

To see this let's suppose that the "response random variable $\mathrm{Y}^{\prime \prime}$ has mean $E[Y]=\mu$ and variance $\sigma^{2}=\operatorname{VAR}(\mathrm{Y})$; if we transform the original response $\mathrm{Y}$ to the "transformed response $\mathrm{RV} \mathrm{U}^{\prime \prime}$ as $\mathrm{U}=\mathrm{h}(\mathrm{Y})$ we can have the approximation of the function $h$, around $\mu, U \approx h(\mu)+(Y-\mu) h^{\prime}(\mu)$, so that $\operatorname{Var}[\mathrm{U}] \approx \operatorname{Var}\left[\mathrm{h}(\mu)+(\mathrm{Y}-\mu) \mathrm{h}^{\prime}(\mu)\right]=\left[\mathrm{h}^{\prime}(\mu)\right]^{2} \operatorname{Var}(\mathrm{Y})=\left[\mathrm{h}^{\prime}(\mu)\right]^{2} \sigma_{\mathrm{Y}}^{2}$. If the standard deviation $\sigma_{Y}$ of the "response random variable $\mathrm{Y}^{\prime \prime}$ depends on the mean $\mathrm{E}[\mathrm{Y}]=\mu$, according to a function $\varphi(\mu)$, by taking $h^{\prime}(\mu)=1 / \varphi(\mu)$, we have $\operatorname{Var}[\mathrm{U}] \approx 1$; therefore the variance becomes "constant (almost)".
A scholar has three ways to find the value of the parameter $\lambda$ of the power "transformed response RV $\mathrm{Y}^{\lambda / \prime}$ :

a) If $\varphi(\mu) \propto \mu^{\alpha}$ and we transform the original response $Y$ to $\mathrm{Y}^{\lambda}$ we can find the gradient $d \mathrm{Y}^{\lambda} / \mathrm{d} \mathrm{Y}=\mathrm{Y}^{\lambda-1}$ of the function $\mathrm{Y}^{\lambda}$ so that $\sigma_{\mathrm{Y}}{ }^{\lambda} \propto \mathrm{dY} / \mathrm{dY} \sigma_{\mathrm{Y}}=\mu^{\lambda-1} \mu^{\alpha}$ [the gradient evaluated at $\mu$; choosing $\lambda+\alpha-1=0$ the "transformed response $\mathrm{RV} \mathrm{Y}^{\lambda \prime}$ has constant variance. Sometimes we know theoretically the relationship $\sigma_{Y}=\varphi(\mu) \propto \mu^{\alpha}$ and we can take advantage of that; for example, if we know that the exponential distribution is suitable to the data on hand, we know that $\sigma_{Y}=\mu$ and therefore $\lambda=0$ : the transformation of the data is $\ln (Y)$, because $\mathrm{Y}^{\lambda}=\exp [\lambda \ln (\mathrm{Y})]=1+\lambda \ln (\mathrm{Y})+[\lambda \ln (\mathrm{Y})]^{2} / 2+[\lambda \ln (\mathrm{Y})]^{3} / 6+\ldots$ so that we have the $\operatorname{limit}\left(\mathrm{Y}^{\lambda}-1\right) / \lambda=\ln (\mathrm{Y})$ for $\lambda \rightarrow 0 \ldots$

b) If we do not know theoretically the relationship $\sigma_{Y}=\varphi(\mu) \propto \mu^{\alpha}$ we can take advantage of the data. We need replicated data so that we can compute $s_{i}$ (estimate of $\sigma_{i}$ ) and $\mathrm{m}_{\mathrm{i}}$ (estimate of $\mu_{\mathrm{i}}$ ) for any $\mathrm{i}$-th experimental condition: since $\sigma_{\mathrm{i}} \propto \mu_{\mathrm{i}}^{\alpha}$, then $\ln \left(\sigma_{\mathrm{i}}\right)=$ constant $+\alpha \ln \left(\mu_{\mathrm{i}}\right)$, a straight line with slope $\alpha$. We compute a the estimate of $\alpha$ and we estimate $\lambda=1-\mathrm{a}$. If $\mathrm{a}=2$ then the "transformed response $\mathrm{RV}^{\prime \prime}$ would be the reciprocal $\mathrm{Y}^{-1}$.

The transformation does not assure by itself that the "transformed response RV" is normally distributed. To get this result we need the $3^{\text {rd }}$ way:

c) We postulate that the normal distribution apply to the error of the "transformed response RV $\mathrm{Y}^{\lambda \prime \prime}$ in the linear model "matrix" $\mathrm{W}=\mathrm{X} \beta+\mathrm{E}$ (see the ANOVA in any good book), where $W=\left(Y^{\lambda}-1\right) / \lambda$; the Mean Square Residual (Sum of Square Residual/df) in the ANOVA table, which we get with the Maximum Likelihood Method, depends on $\lambda$; let's name it $\operatorname{MS}_{R}(\lambda)$. We compute a set of values $\operatorname{MS}_{R}\left(\lambda_{1}\right), \operatorname{MS}_{R}\left(\lambda_{2}\right), \ldots$, $\operatorname{MS}_{\mathrm{R}}\left(\lambda_{\mathrm{n}}\right)$, and we chose as estimate of $\lambda$ the one $\lambda^{0}$ providing the minimum $\operatorname{MS}_{\mathrm{R}}\left(\lambda^{0}\right)$. Obviously this depends on the data and on the assumed model... \{remember that $\mathrm{Y}^{\lambda}=\exp [\lambda \ln (\mathrm{Y})]=1+\lambda \ln (\mathrm{Y})+[\lambda \ln (\mathrm{Y})]^{2} / 2+[\lambda \ln (\mathrm{Y})]^{3} / 6+\ldots$ and $\left.\mathrm{Y}^{\lambda}-1=\lambda \ln (\mathrm{Y})+\ldots\right\}$

Since the Maximum Likelihood method is NOT an optimisation method we see that the QEG statement ««... exponential $\mathrm{y}^{*}=\mathrm{y}^{\lambda}$, where $\lambda$ is the parameter of the transformation... optimization method for determining the transformation parameter»») is FALSE!!!

Let's go back to the QEG data.

\section{The Experiments Carried Out; Comparison with a Previous Experiment}

What can a scholar do with the DOE shown in the paper [33] (2010)?

Let's see. There are 105 treatment combinations replicated 5 times (see the table in figure 6).

For each of these combinations, 50 measurements of the TOF are performed, taking the average value.

As QEG did in the book, they say:

"Analyzing the factorial plan experimental outputs, the first 
interesting result is that the TOF $F_{\text {Error }}$ standard deviation ( $\sigma$ ) changes depending on the TOF Error value. (for each of the 525 factorial plan combinations the average TOF Error and the respective standard deviation are calculated using the corresponding 50 repeated measurements). It can be noticed that the larger the average TOF Error value, the larger the individual measurement dispersion. The nonhomogeneity of the TOF Error variance is also tested through Levene's statistical test at $p<0.05$. Since the assumption of homogeneity of the TOF $F_{\text {Error }}$ variances is violated, ANOVA cannot properly be applied to verify whether factors have a significant effect on the response $\left(T O F_{\text {Error }}\right)$ and whether there are factor interactions. The usual approach to dealing with nonhomogeneous variance is to apply a variance-stabilizing transformation. In this approach, the conclusions of the ANOVA will apply to the transformed populations. The most common transformation is the exponential $y *=y^{\lambda}$, where $\lambda$ is the parameter of the transformation. Box and Cox proposed an optimization method for determining the transformation parameter [FALSE! see later]. Once a value of $\lambda$ is selected by the Box-Cox method, the experimenter can analyze the data using $y *$ as the transformed response (it will be identified

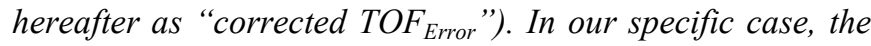
obtained transformation parameters $\lambda=0.52$. Applying Levene's test to the transformed response, the resulting variance no longer violates the test's null hypothesis of homogeneity. Of course, a problem is that it may be unpractical working with the transformed response $(y *)$ in the transformed scale, since it can result in a nonsensical value over the factor space of interest. To construct a model in terms of the original response, the opposite change of variable- $(y *)^{1 / \lambda}$-is performed."

LIST OF THE EXPERIMENTS CARRIED OUT ON THE CRICKet's US TRANSDUCERS

\begin{tabular}{|c|c|c|c|}
\hline \multicolumn{4}{|c|}{ Factors } \\
\hline & $\begin{array}{c}1^{\text {s }}-\begin{array}{l}\text { Transceivers } \\
\text { distance }(d)\end{array}\end{array}$ & $\begin{array}{l}2^{\text {nd }}-\text { Transmitter } \\
\text { misalignment angle }(\theta)\end{array}$ & $\begin{aligned} & 3^{\text {nd }}- \text { Battery } \\
& \text { level (V) }\end{aligned}$ \\
\hline \multirow{7}{*}{$\begin{array}{l}\frac{\infty}{d} \\
\frac{3}{3}\end{array}$} & (Short) $\quad d_{1}=1160 \mathrm{~mm}$ & $\boldsymbol{\theta}_{1}=0^{\circ}$ & \\
\hline & & $\theta_{2}=10^{\circ}$ & $\mathrm{V}_{1}=2.7 \mathrm{~V}$ \\
\hline & (Medium $\mathrm{d}=2034 \mathrm{~mm}$ & $\boldsymbol{\theta}_{3}=20^{\circ}$ & $V_{2}=2.6 \mathrm{~V}$ \\
\hline & (Medium) $d_{2}=2034 \mathrm{~mm}$ & $\theta_{4}=30^{\circ}$ & $\mathrm{V}_{3}=2.5 \mathrm{~V}$ \\
\hline & $(\mathrm{gng}) \quad \mathrm{d}=3671 \mathrm{~mm}$ & $\theta_{5}=40^{\circ}$ & $\mathrm{V}_{4}=2.4 \mathrm{~V}$ \\
\hline & (Long) $\quad a_{3}-50 / 7 \mathrm{~mm}$ & $\theta_{6}=50^{\circ}$ & $\mathrm{V}_{5}=2.3 \mathrm{~V}$ \\
\hline & & $\theta_{7}=60^{\circ}$ & \\
\hline
\end{tabular}

- all the possible 7.3.5 $=105$ different combinations are carried out in random order; for each combination, TOF measurements are repeated 50 times and the average value is taken:

all the 105 combinations above are replicated 5 times; consequently, the total number of combinations is 525 .

Figure 6. Excerpt from the paper (2010).

QEG statement ««The most common transformation is the exponential $\mathrm{y}^{*}=\mathrm{y}^{\lambda}$, where $\lambda$ is the parameter of the transformation. Box and Cox proposed an optimization method for determining the transformation parameterı!) is FALSE because the Maximum Likelihood method is used, which is NOT an optimisation method!!!

These transformed data (original data or means?, the QEG do not say anything about this...) are the data analysed; the ANOVA, of QEG, is in their figure 12 (figure is 7 in this paper)

General Linear Model: corrected TOF error versus d; $\theta$; V
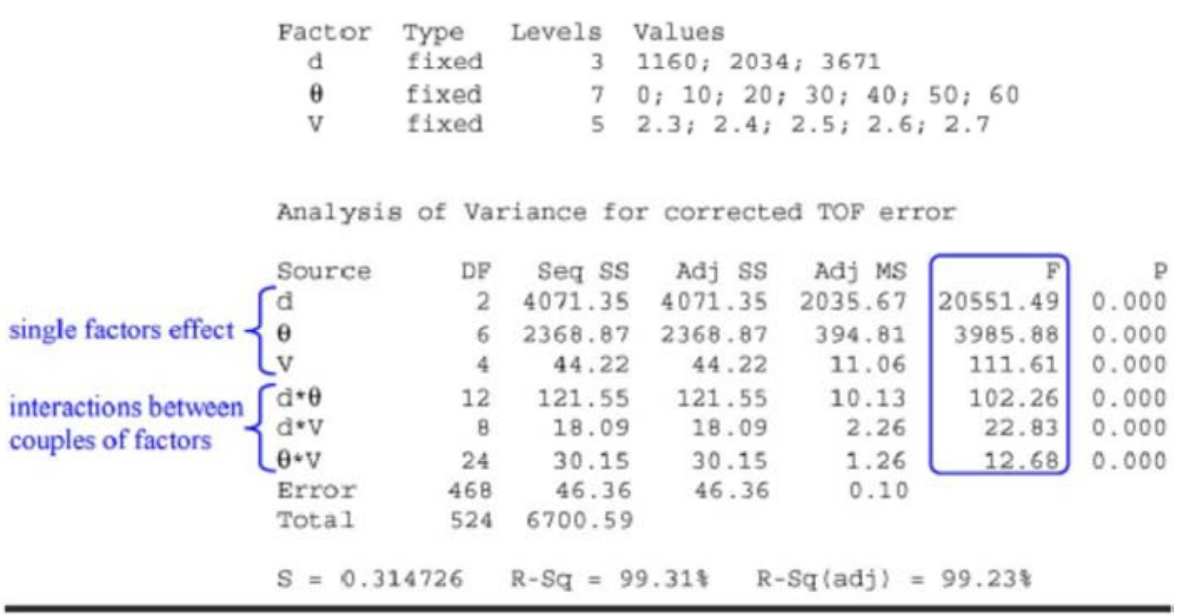

Fig. 12. ANOVA applied to the (transformed) response of the factorial plan.

Figure 7. Excerpt from the paper [33] 2010).

Let's analyse the output of Minitab statistical software!

QEG figure 12 (Figure 7 in this paper) shows 7 levels for $\theta$.

QEG figure shows a "Total DF=524"!!! They used only the means of the 50 data, collected for each treatment combination!!!

QEG transformed the data with $\lambda=0.52$; did they transformed the original data or only the means?

The 3 factors and their $1^{\text {st }}$ order (two-factor) interactions are significant.

From the QEG ANOVA table we can derive the following table 
Table 1. ANOVA, derived by Figure 7.12 of QEG paper.

\begin{tabular}{lllllll}
\hline Fausto Galetto ANOVA, derived by Figure 7.12 of QEG paper & & & \\
\hline Source & df & SS & MS & Fc & F* & \\
\hline Corrected Total & 524 & 6710.59 & & $\alpha=$ & 0.01 & \\
d & 2 & 4071.35 & 2035.675 & 6894.10 & 4.648 & $* *$ \\
$\theta$ & 6 & 2368.87 & 394.812 & 1337.09 & 2.838 & $* *$ \\
d $\theta$ & 12 & 121.55 & 10.129 & 34.30 & 2.220 & $* *$ \\
Error (Residual) & 504 & 148.82 & 0.295 & & & \\
\hline
\end{tabular}

We see that the 2 factors $d$ and $\theta$ and their interaction $\mathrm{d} \theta$ are significant as they are in the [32] book for Exploratory experiments.

Anyone can compare this Fausto Galetto ANOVA with the one of the [32] book for Exploratory experiments (in table 2):

a) 50 data per treatment combination

b) average values (means) used for computation in the ANOVA with 2 factors

c) variance stabilising transformations with $\lambda=0.17$ (in the book [32] and $\lambda=0.52$ (in the paper [33]); did they transformed the data or only the means? QEG did not tell us!

d) what about the Confidence Intervals of the two $\lambda=0.17$ (in the book [32]) and $\lambda=0.52$ (in the paper [33])

e) factor $\mathrm{d}: 3$ levels for both situations

f) factor $\theta: 4$ levels (for the Exploratory experiments) vs 7 levels (for the paper experiments)

g) interaction $\mathrm{d} \theta$ : the $\mathrm{df}$ are accordingly different

h) the importance of factors and interaction, provided by the SS (Sum of Squares) and related MS (Mean Squares) are completely different

i) the computed values $\mathrm{F}$ (Fc, for Fausto Galetto) are therefore completely different

j) for both situations, factors and interaction are significant (does that mean that the 2 situations are to be considered equivalent? QEG did not consider this point!)

$\mathrm{k}$ ) the ratios of $M S$ (Mean Squares) of (two situations) factors and interaction are significant [table 3]!!! [at $1 \%$ level]

1) that means that the two experimental situations CANNOT be used.... UNLESS....

Table 2. ANOVA, derived by Figure 7.11 of QEG book.

\begin{tabular}{|c|c|c|c|c|c|c|}
\hline \multicolumn{7}{|c|}{ Fausto Galetto ANOVA, derived by Figure 7.11 of QEG book Exploratory experiments } \\
\hline Source & df & SS & MS & Fc & $\mathbf{F}^{*}$ & Sig \\
\hline Corrected Total & 35 & 0.325583 & & $\alpha=$ & 0.01 & \\
\hline d & 2 & 0.078990 & 0.039495 & 4885.98 & 5.614 & ** \\
\hline$\theta$ & 3 & 0.243035 & 0.081012 & 10022.06 & 4.718 & $* *$ \\
\hline $\mathrm{d} \theta$ & 6 & 0.003364 & 0.000561 & 69.36 & 3.667 & $* *$ \\
\hline Error (Residual) & 24 & 0.000194 & 0.000008 & & & \\
\hline
\end{tabular}

Table 3. Comparison ANOVA, of QEG paper and book.

\begin{tabular}{llll}
\hline & ratio of MS (Mean Squares) of (two situations) & F $^{*}$ & Significance \\
\hline ratios for & $\alpha=$ & $\mathbf{0 . 0 1}$ & $* *$ \\
\hline $\mathrm{d}$ & 51542.60 & 99.000 & $* 11$ \\
$\theta$ & 4873.52 & 27.911 & $* *$ \\
$\mathrm{~d} \theta$ & 18066.29 & 7.718 & $* *$ \\
\hline
\end{tabular}

Why such a big difference? Different layout of transceivers? Different measurands? Different $\lambda$ ?

We cannot do anything more to find out the truth....

We do not have the data (unfortunately...)!

\section{The Experiments Carried Out; Second Part of the Book}

Let's see the book [32] at $\S$ 7.2.3.2 Results of the Detailed Experiments. QEG does say:

"Results of detailed experiments are graphically represented in Figures 7.12 and 7.13. They represent the average $\mathrm{TOF}_{\text {Error }}$ and the corresponding standard deviation (calculated, for each combination of factors, using the 50 repeated measurements) depending on $\mathrm{d}$ and $\theta \ldots$ we can notice that $\mathrm{TOF}_{\text {Error }}$ increases with an increase in $\mathrm{d}$ and $\theta$.
Again, $\mathrm{TOF}_{\text {Error }}$ is always positive, because of the TOF overestimation due to the signal attenuation (which is proportional to $\mathrm{d}$ and $\theta$ ). In particular, the relationship between $\mathrm{TOF}_{\text {Error }}$ and $\mathrm{d}$ appears approximately linear, while the relationship between $\mathrm{TOF}_{\text {Error }}$ and $\theta$ appears approximately quadratic. Also, it can be noticed that $\mathrm{TOF}_{\text {Error }}$ measurements cannot be performed when the two factors have both large values -i.e. when $\theta=45^{\circ} \mathrm{C}$ and $\mathrm{d}=3,500 \mathrm{~mm}$, and when $\theta=60^{\circ} \mathrm{C}$ and $\mathrm{d}=1,500 \mathrm{~mm}$. In fact, in all these conditions transmitter and receiver are not able to communicate because of the strong signal attenuation (receiver beyond the transmitter's cone of communication).... the $\mathrm{TOF}_{\text {Error }}$ standard deviation tends to increase while increasing the received US signal attenuation..."

NOTICE: no ANOVA was performed! Meditate...

Why? the Design is not Balanced! QEG did not have the Theory... QEG used only graphs!!! Scientific attitude...??? 
QEG therefore reverted to "§ 7.2.4 Model Construction" and said:

"In this section we propose an experimental regressive model to link $\mathrm{TOF}_{\text {Error }}$ with $\theta$ and $\mathrm{d}$. The total number of observations that were used to construct the model is given by 37 combinations with 50 repetitions per combination, which corresponds to 1,850 TOF measurements. Analyzing the graph patterns in Figure 7.12 and based on the knowledge of the physical phenomenon investigated, a second order polynomial model was chosen... we refer the reader to the relevant literature."

We provide, in figure 8, the excerpt taken from the book [32] ("large model").

Notice the QEG wrong statement in the Excerpt (Figure 8) ««... the chosen model makes it possible to evaluate the factors interaction»»): $\mathrm{K}_{6} \mathrm{~d} \theta$ is NOT "the factors interaction" but ONLY the interaction of the linear effects both of $d$ and $\theta$; in fact, in the formula $7.4, \mathrm{~K}_{6} \mathrm{~d} \theta$ accounts for $1 \mathrm{df}$ and NOT for $32=(5-1)(9-1) \mathrm{df} ! ! !$

The members of QEG went on by saying [see figures 8 and 9]:

"With the support of the Minitab_Best-Subsets tool, we find that the terms with coefficients $\overline{\mathrm{K}}_{3}$ and $\mathrm{K}_{4}$ have slightly influential contributions [our figure 8]. In fact, considering several competing multiple regression models of order not larger than two (see Figure 7.15), the model with the three terms $\left(\mathrm{d}, \theta^{2}\right.$ and $\left.\mathrm{d} \theta\right)$ is the one with the Mallows' $\mathrm{Cp}$ (4.3) closest to the number of predictors plus the constant (4). In general, Mallows' $\mathrm{Cp}$ is used in statistics to assess the fit of a regression model that has been estimated using ordinary least squares. It is applied in the context of model selection, where a number of predictor variables are available for predicting some outcome, and the goal is to find the best model involving a subset of these predictors. As anticipated, the best model is the one with the Mallows' $\mathrm{Cp}$ closest to the number of predictors plus the constant (Mallows 1973). In this specific case, this fact was also confirmed by an initial regression, based on the model in Eq. 7.4, in which the contribution of the terms $d, \theta^{2}$ and $d \theta$ appeared to be secondary[our figure 9!!!]."

Notice (and meditate) the QEG contradiction ««this fact was also confirmed by an initial regression, based on the model in Eq. 7.4 ("large model"), in which the contribution of the terms $d, \theta^{2}$ and $d \theta$ appeared to be secondary.»"»: IF the terms $\mathrm{d}, \theta^{2}$ and $\mathrm{d} \theta$ were NOT "important", i.e. "NOT significant", they CANNOT become "significant" in the formula 7.5 ("reduced model")!!!

We do not have the data... Therefore we must accept that (take it or leave it): "As a consequence, terms with coefficients $\mathrm{K}_{3}$ and $\mathrm{K}_{4}$ were removed from the model and a new second order model, representing a compromise solution between best-fitting and reduction of the number of predictors was constructed using Eq. 7.5. ("reduced model")

The two formulae are numbered as QEG did: they are excerpts.

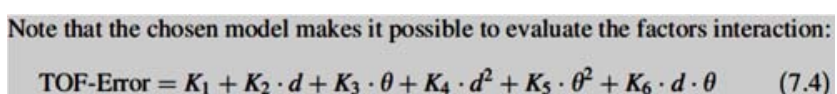

TOF-Error $=K_{1}+K_{2} \cdot d+K_{3} \cdot \theta+K_{4} \cdot d^{2}+K_{5} \cdot \theta^{2}+K_{6} \cdot d \cdot \theta$

Figure 8. Excerpt from the book (“large model”).

TOF-Error $=K_{1}+K_{2} \cdot d+K_{5} \cdot \theta^{2}+K_{6} \cdot d \cdot \theta$

Figure 9. Excerpt from the book ("reduced model"),

Notice (and meditate) the QEG wrong statement that follows the Excerpt (figure 9) ««It is important to note the presence of the last term $\left(K_{6} d \theta\right)$, which accounts for the interaction between the two factors. "): $\mathrm{K}_{6} \mathrm{~d} \theta$ is NOT "the interaction between the two factors" but ONLY the interaction of the linear effects both of $\mathrm{d}$ and $\theta$; in fact, in the formula $7.4, \mathrm{~K}_{6} \mathrm{~d} \theta$ accounts for $1 \mathrm{df}$ and NOT for $32=(5-1)(9-1)$ df!!! [see figure 10 of the weighted regression]

Moreover the regression coefficients $\mathrm{K}_{\mathrm{i}}$ are different in the formulae (7.4) and (7.5) [as it should be].

The members of QEG go on by saying:

"Since the variance of the response variable (TOF-Error) is not homogeneous, a simple linear regression is not perfectly suitable. In particular, heteroscedasticity may have the effect of giving too much weight to subset of the data where the error variance is larger, when estimating coefficients. To reduce standard error associated with coefficient estimates, in regression in which homoscedasticity is violated, a common approach is to weight observations by the reciprocal of the estimated point variance. For each observation, the variance is calculated using the 50 repetitions associated to the corresponding factor combination (numerical values of the $r$ related to each factor combination are reported in Figure 7.13). The final regression equation is:

TOF-Error $=84.6+0.0207 \mathrm{~d}+0.0314 \theta^{2}+0.000336 \mathrm{~d} \theta$

In Eq. 7.6 [figure 10, weighted regression], $\mathrm{TOF}_{\text {Error, }} \mathrm{d}$ and $\theta$ are respectively expressed in $\mu \mathrm{s}, \mathrm{mm}$ and degrees $\left(^{\circ}\right)$. This model can be useful for correcting the systematic error in TOF measurements. Given that the variation in the response standard deviation is not very large, it emerged that Eq. 7.6 [figure 10, weighted regression] is not very dissimilar to the result that would be obtained by a simple (non weighted) linear regression.

The QEG members go on by saying:

"The regression output is quantitatively examined by an ANOVA (see Figure 7.16) [you see it in "our" Figure 10]. Based on $t$ test at $p<0.05$, it can be sentenced that all the terms in Eq. 7.6 are significant. Examining the residuals, they can be considered as randomly distributed by the Anderson-Darling normality test at $\mathrm{p}<0.05$. The model fits well with experimental data."

That is what we, as readers, have: "Take it or leave it!". 
(Weighted) Regression Analysis: TOF-Error versus $d, \theta$ and $d \cdot \theta$

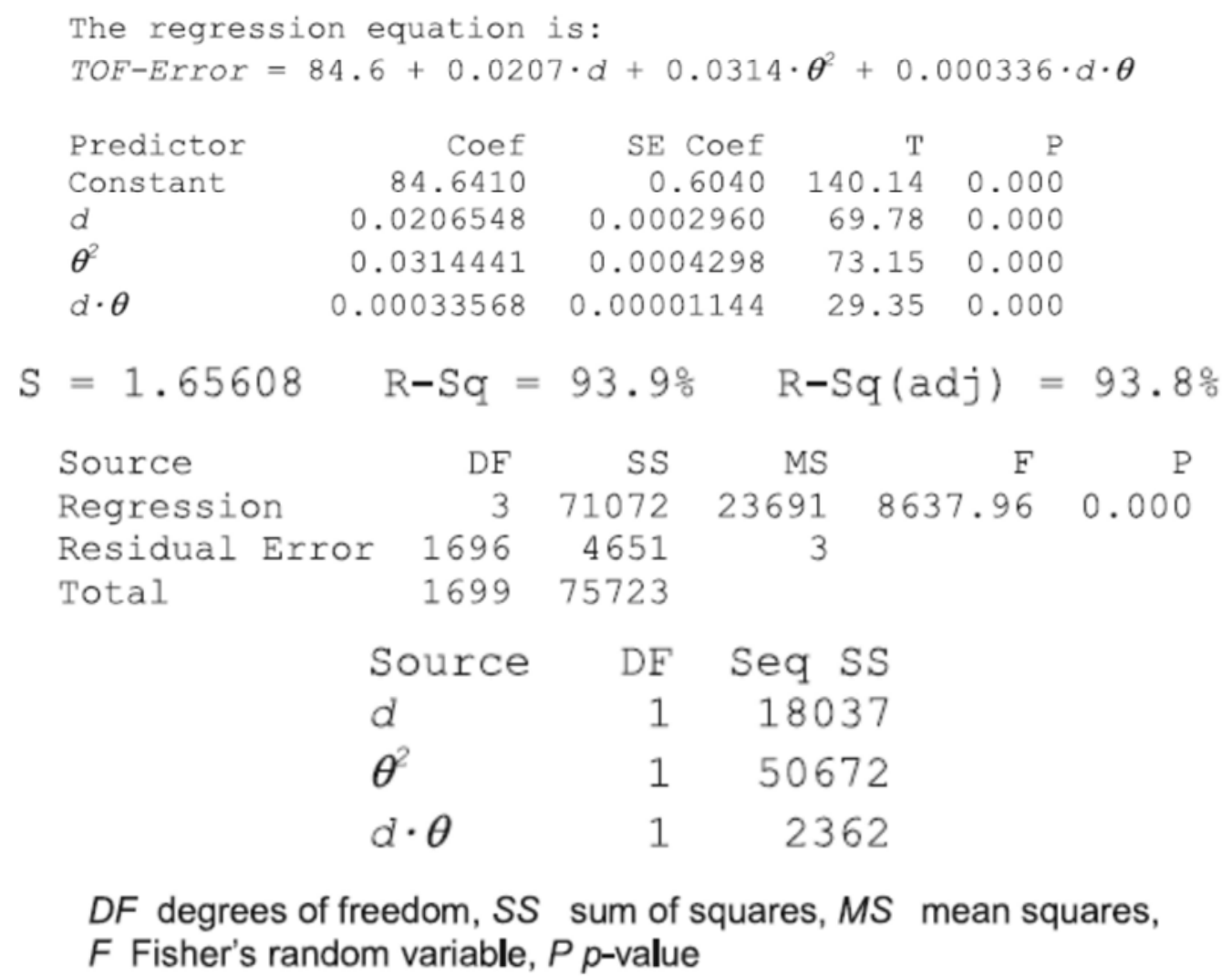

Fig. 7.16 Results of the (weighted) regression analysis. Analysis is carried out using Minitab ${ }^{\circledR}$ Statistical software

Figure 10. Excerpt from the book [32].

\section{Analysis of the Experiments Carried Out, Using SPQR}

Let's see, on the contrary to the QEG findings, the SPQR in action

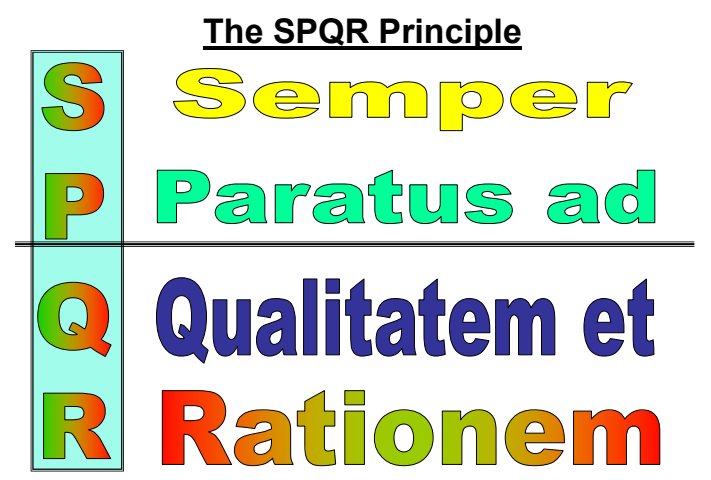

Figure 11. The SPQR Principle.
Since 37 runs times 50 data (per run) gives a total number of data 1850, from the ANOVA of QEG we deduce that only a total of data 1700 were used: 150 data (3 runs) were discarded; which? They are the 3 runs at $60^{\circ} \mathrm{C} ! ! !$

See the figure 12 taken from the book [32].

Those 3 points (runs) would have generated quite different estimates of the regression coefficients and perhaps quite a different formula!!!

We use the QEG regression formula

$\mathrm{TOF}_{\text {Error }}=84.6+0.0207 \mathrm{~d}+0.0314 \theta^{2}+0.000336 \mathrm{~d} \theta$

to generate the data on the 34 runs carried out [comparing them with the points in the graphs] and on the 3 missing (we do that to easily use the orthogonal contrasts giving a great insight in the matter).

Comparing the QEG graph with the Simulated data of the $Q E G$ formula it is clear that the important curvature is lost!

Moreover it is clear, for people who know a little of Mathematics, that there is a linear effect of $\theta$ !!! (see the following graphs, in the figure 14) 
(a) Average TOF-Error vs Distance between Transceivers

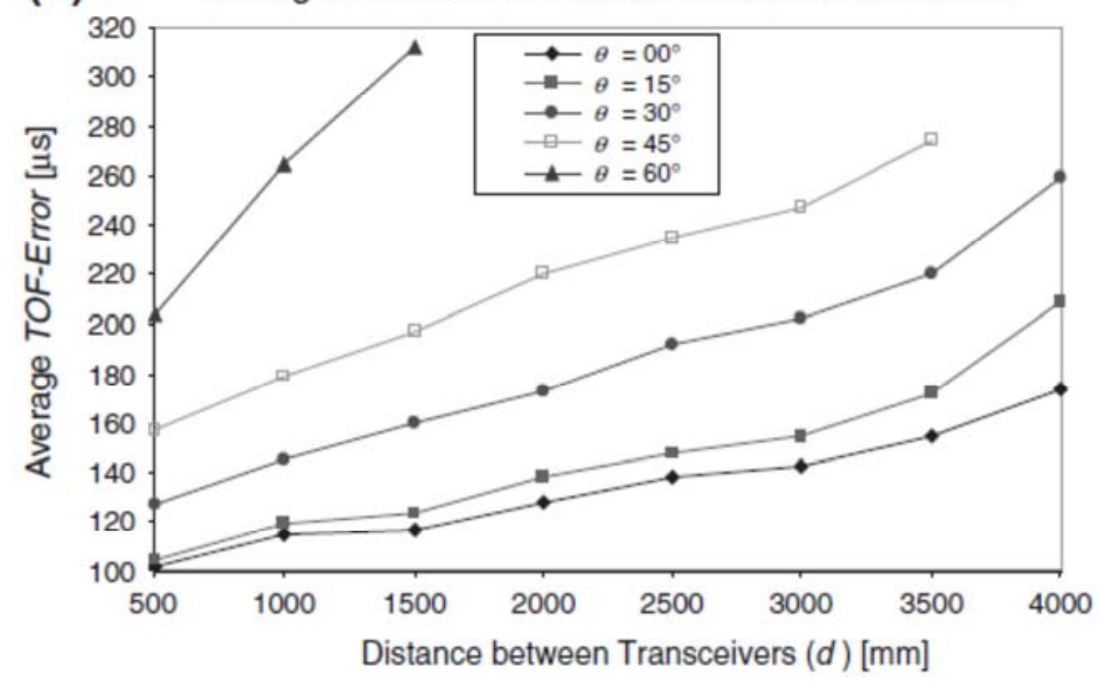

Figure 12. Excerpt from the book [32] (there it is Figure 7.12).
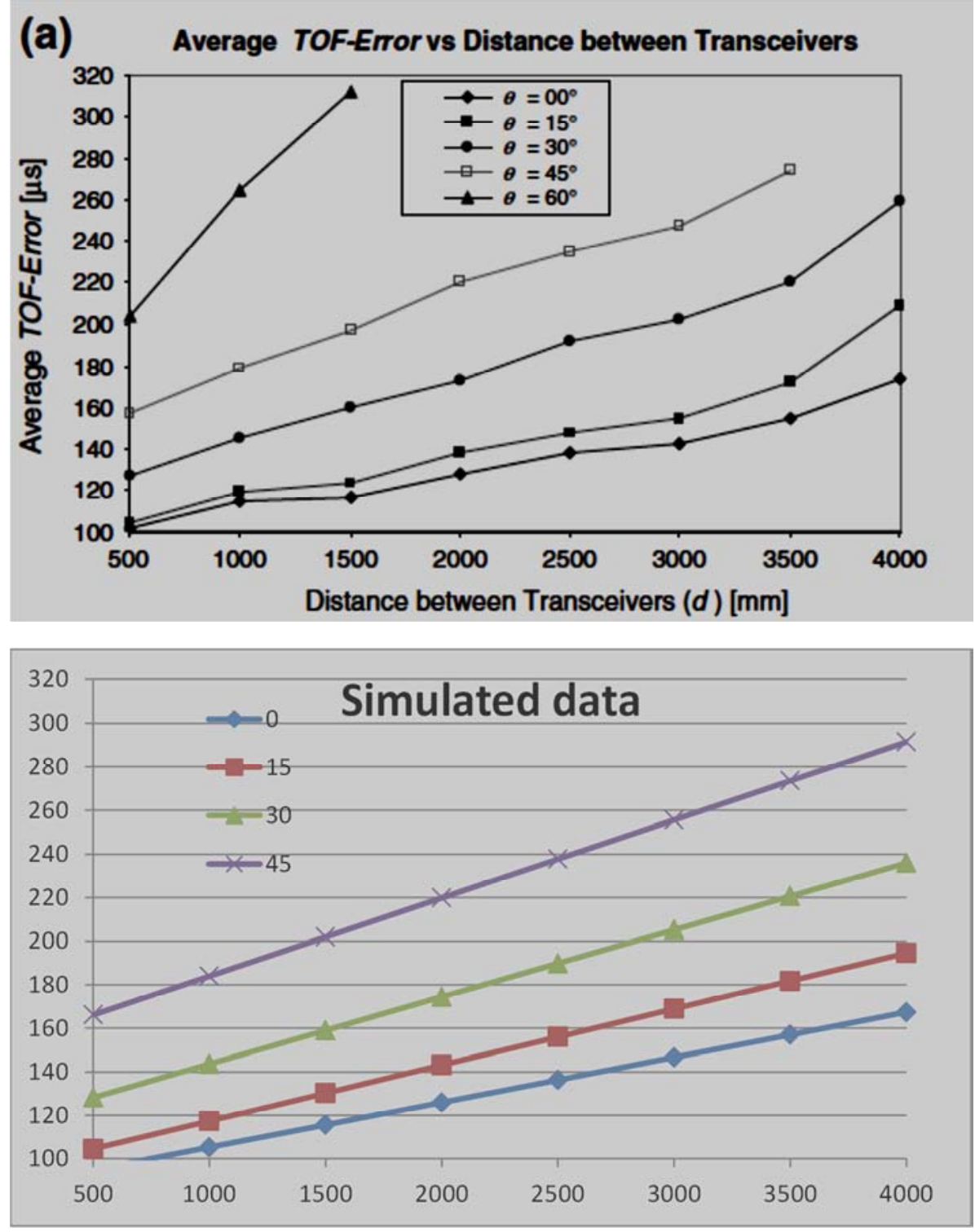

Figure 13. Comparison of the actual data (means) with the data found using the regression 7.6. 

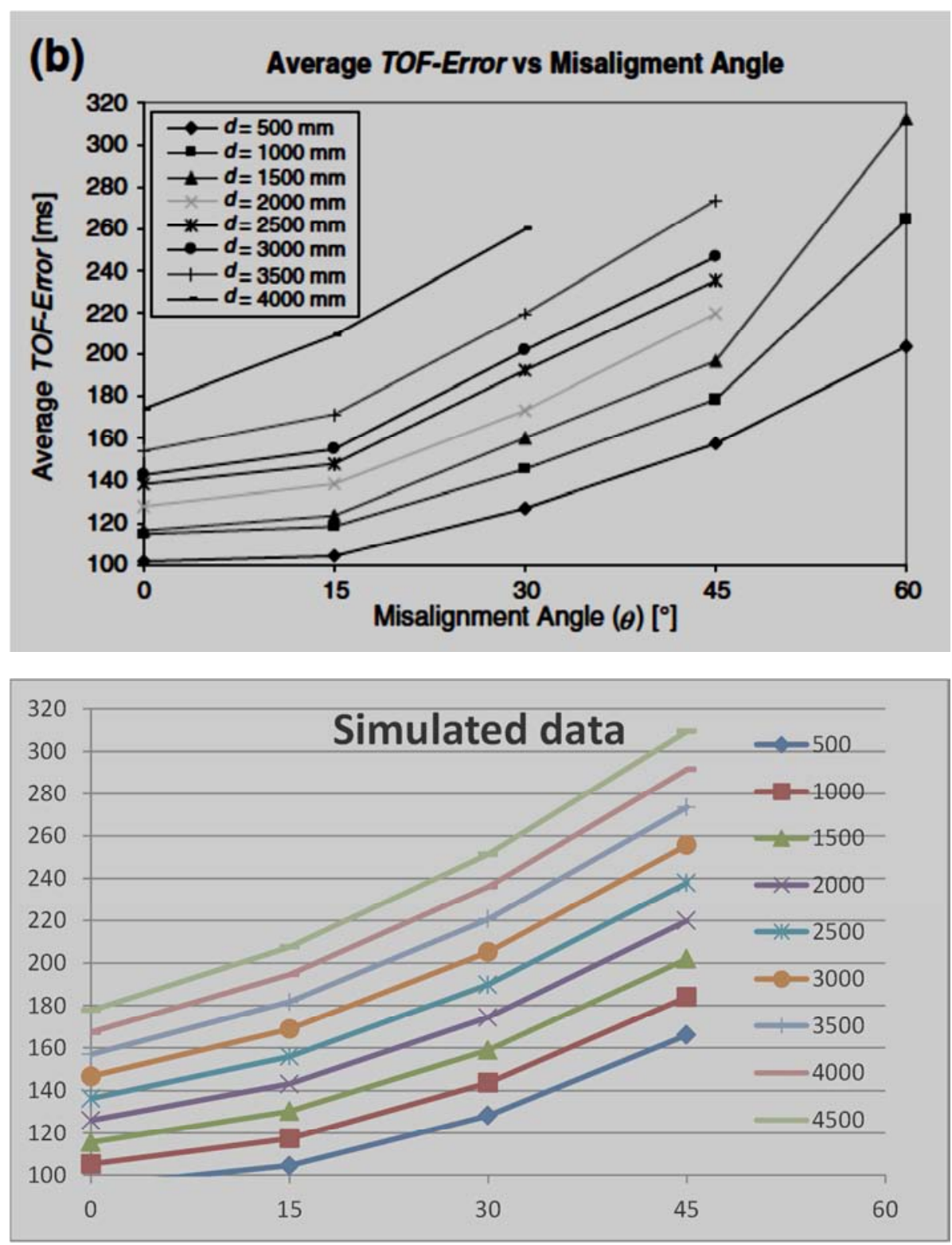

Figure 14. Comparison of the actual data (means) with the data found using the regression 7.6.

Using the orthogonal contrasts for the Linear effect of $\mathrm{d}$, $\mathrm{d}_{\text {Linear, }}$, the Linear effect of $\theta, \theta_{\text {Linear }}$, the Quadratic effect of $\theta$ [due to $\theta^{2}$ ], $\theta_{\text {Quadratic }}$, and the effect of the interaction of Linear effect of $d$ and the Linear effect of $\theta, d \theta_{\text {Linear,Linear, }}$ one finds the following ANOVA table, where all the effects in it are significant at 0.0001 level:

Table 4. Significant effects, at 0.0001 level [notice], in the regression: $\theta_{\text {Linear }}$ was missed by $Q E G$.

\begin{tabular}{lll}
\hline Source & df & SS_MS \\
\hline mean & 1 & 1179707.94 \\
$\mathrm{~d}_{\text {Linear }}$ & 1 & 52372.95 \\
$\theta_{\text {Linear }}$ & 1 & 51804.11 \\
$\theta_{\text {Quadratic }}$ & 1 & 2108.35 \\
$\mathrm{~d}_{\text {Linear }} \theta_{\text {Linear }}$ & 1 & 2630.07 \\
\hline
\end{tabular}

It is clear that the linear effect $\theta_{\text {Linear }}$ of the factor $\theta$ is highly significant, while $\theta_{\text {Linear }}$ was missed by QEG.

The coefficients of the regression formula [with the orthogonal polynomials] are in table 5

Table 5. Coefficients of the regression formula [with the orthogonal polynomials].

\begin{tabular}{lllll}
\hline $\mathbf{1 8 1 . 0 2 4}$ & $\mathbf{0 . 0 2 9 5}$ & $\mathbf{2 . 2 6 2}$ & $\mathbf{0 . 0 3 4 0}$ & $\mathbf{0 . 0 0 0 3 9 5}$ \\
\hline mean & $\mathrm{d}_{\text {Linear }}$ & $\theta_{\text {Linear }}$ & $\theta_{\text {Quadratic }}$ & $\mathrm{d}_{\text {Linear }} \theta_{\text {Linear }}$ \\
\hline
\end{tabular}

Compare this finding with the following QEG formula (7.6)

TOF-Error $=84.6+0.0207 d+0.0314 \theta^{2}+0.000336 \mathrm{~d} \theta$

It is clear that QEG missed the significant linear effect $\theta_{\text {Linear }}$.

Now we use the QEG graphs to "generate"the data of the complete experiment and we will use the G-Method to find the estimates...

Since we did not have the original data, we decided to "use" the data "recovered" from the graphs. Here they are: 
Table 6. Data (34) recovered from the graphs.

\begin{tabular}{lccccc}
\hline \multicolumn{2}{l}{ disalignment angle ${ }^{\circ} \mathbf{C}$} & & & & \\
\hline distance & $\mathbf{0}$ & $\mathbf{1 5}$ & $\mathbf{3 0}$ & $\mathbf{4 5}$ & $\mathbf{6 0}$ \\
\hline 500 & 102 & 104 & 128 & 158 & 200 \\
1000 & 117 & 118 & 145 & 172 & 258 \\
1500 & 118 & 123 & 159 & 197 & 310 \\
2000 & 130 & 137 & 175 & 218 & \\
2500 & 137 & 147 & 183 & 232 & \\
3000 & 142 & 151 & 199 & 238 & \\
3500 & 154 & 170 & 218 & 267 & \\
\hline
\end{tabular}

\begin{tabular}{lccccc}
\hline \multicolumn{2}{l}{ disalignment angle ${ }^{\circ} \mathbf{C}$} & & & & \\
\hline distance & $\mathbf{0}$ & $\mathbf{1 5}$ & $\mathbf{3 0}$ & $\mathbf{4 5}$ & $\mathbf{6 0}$ \\
\hline 4000 & 175 & 210 & 258 & & \\
\hline
\end{tabular}

Since we do not have the QEG original data we can only use the data from the graphs in order to find the value of $\lambda$; doing that we find a value -0.54 (rounded to -0.5 , reciprocal square root transformation) as given in the following figure:

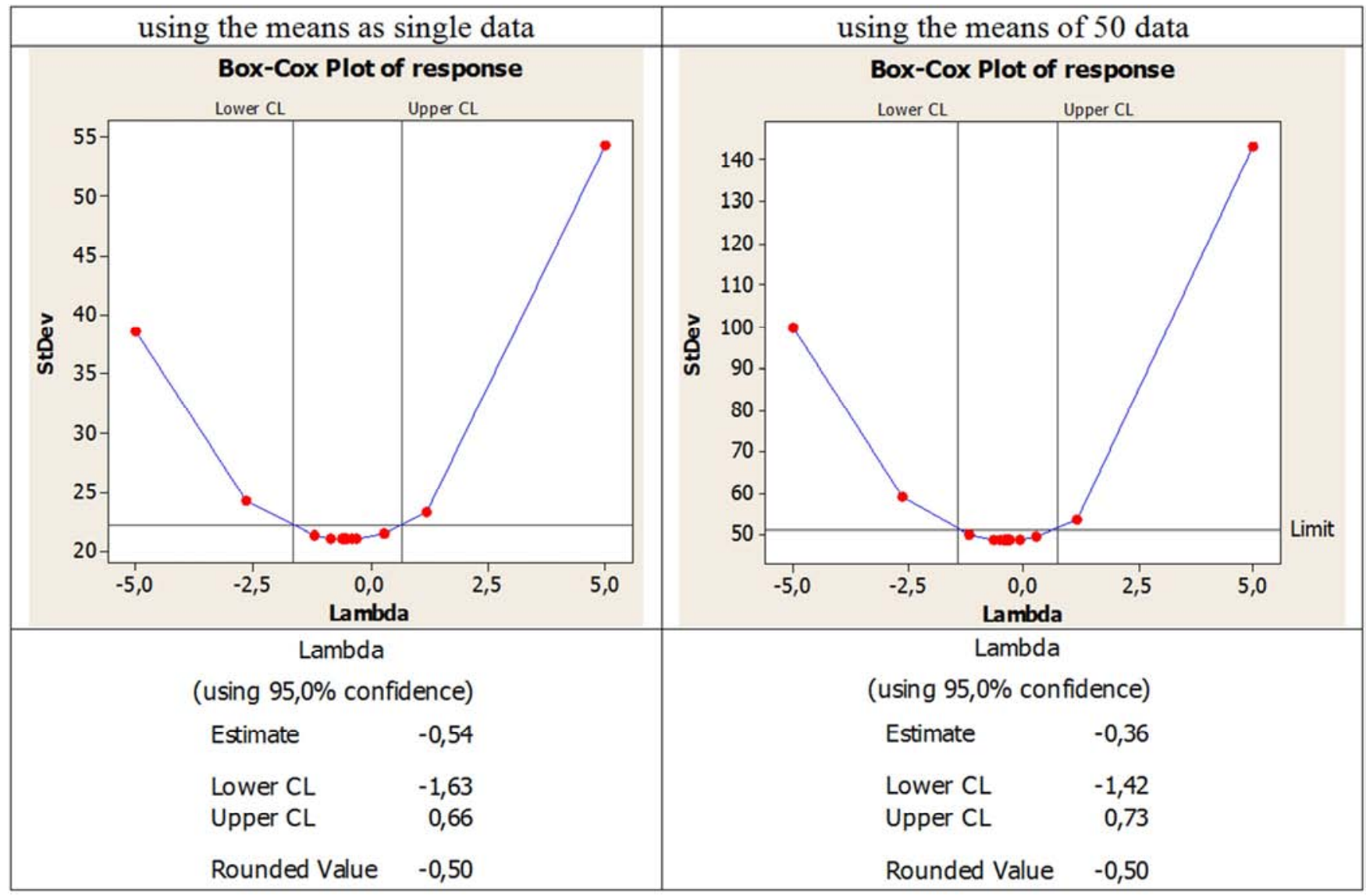

Figure 15. Comparison of the exponent $\lambda$ for VST, 34 transformed data (from the graphs, table 6).

Two values of $\lambda$ were computed [see figure 15], on the left assuming that the data on the graphs were single data (34 from the graphs, table 6), on the right assuming that the data on the graphs were means of 50 data.

The Confidence Intervals are $\mathrm{CI}_{1}=[-1.63,0.66]$ and $\mathrm{CI}_{2}=[-1.42,0.73]$ with $C L=95 \%$.

NOTICE: both the Confidence Interval comprise the value 0 and then the $\log$ transformation is acceptable!

NOTICE (and meditate): the QEG members did not provide the Confidence Interval for their estimate of $\lambda$ "In our specific case, the obtained transformation parameters $\lambda=0.52^{\prime \prime}$ (from the 2010 paper [33]): since the value $\lambda=0.52$ is in the Fausto Galetto Confidence Intervals $\mathrm{CI}_{1}=[-1.63,0.66]$ and $\mathrm{CI}_{2}=[-1.42$, $0.73]$ we can conclude that "with $95 \% C L \lambda=0.52$ and $\lambda=-0.54$ (or -0.36) can be considered equivalent"; the transformation parameter $\lambda=0.17^{\prime \prime}$ (from the book, Exploratory experiments) is in the Fausto Galetto Confidence Intervals $\mathrm{CI}_{1}=[-1.63,0.66]$ and $\mathrm{CI}_{2}=[-1.42,0.73]$; we can conclude that "with $95 \% \mathrm{CL}$ $\lambda=0.17$ and $\lambda=-0.54$ (or -0.36 ) can be considered equivalent": moreover, since the value $0 \in \mathrm{CI}_{1}$ and $0 \in \mathrm{CI}_{2}, \log$ transformation could be acceptable!

Without the data we cannot say anything more.... but transforming the 34 data (from the graphs, table 6) and see the related ANOVA [balanced with 40 data]; we use the two values $\lambda=0.50$ [the "rounded" one of QEG] and $\lambda=-0.50$ [the "rounded" one of Fausto Galetto].

NOTICE that we used 40 data (for the ANOVA) to make the analysis "balanced"... to be compared with the one with $\lambda=-0.5$.

The 34 transformed data (from the graphs, table 6 ) have a value $\mathrm{AD}$ (Anderson Darling) $=0.353$.

The Anderson-Darling normality test is defined as:

$\mathrm{H}_{0}$ : The data follow a normal distribution

$\mathrm{H}_{\mathrm{A}}$ : The data do not follow a normal distribution.

Smaller Anderson-Darling values indicates that the distribution fits the data better. 
Table 7. ANOVA with the data recovered from the graphs and transformed with $\lambda=0.5$ [QEG estimate of $\lambda$ ].

\begin{tabular}{|c|c|c|c|c|c|c|}
\hline \multicolumn{7}{|c|}{ ANOVA of the data transformed (of curves) with $\lambda=0.5$, (the QEG estimate of $\lambda$ ) } \\
\hline Source & SS & df & MS & Fc & $F^{*}$ & Signif \\
\hline Total & 8035.00 & 40 & $\alpha=$ & 0.1 & & \\
\hline mean & 7754.93 & 1 & & & & \\
\hline Corrected Tot & 280.07 & 39 & & & & \\
\hline d & 71.29 & 3 & 23.76 & 221.78 & 2.29 & * \\
\hline$\theta$ & 202.80 & 7 & 28.97 & 270.40 & 1.94 & * \\
\hline$d_{L} \theta_{L}$ & 2.04 & 1 & 2.04 & 19.02 & 2.89 & * \\
\hline QEG RES. & 3 & 28 & 0.11 & & & \\
\hline $\mathrm{d}_{\mathrm{L}}$ & 69.78 & 1 & 69.78 & 651.26 & 2.89 & * \\
\hline $\mathrm{d}_{\mathrm{Q}}$ & 0.06 & 1 & 0.06 & 0.53 & 2.89 & \\
\hline$\theta_{\mathrm{L}}$ & 187.90 & 1 & 187.90 & 1753.78 & 2.89 & * \\
\hline$\theta_{Q}$ & 13.85 & 1 & 13.85 & 129.30 & 2.89 & $*$ \\
\hline
\end{tabular}

NOTICE (and meditate): from table 7, we see clearly that the Linear effect $\theta_{\mathrm{L}}$ of the angle is very important: this point is completely missed by QEG!

Let's see the transformation with $\lambda=-0.5$ [Fausto Galetto estimate of $\lambda]$ :

Table 8. ANOVA with the data recovered from the graphs and transformed with $\lambda=-0.5$.

\begin{tabular}{|c|c|c|c|c|c|c|}
\hline \multicolumn{7}{|c|}{ ANOVA of the data transformed (of curves) with $\lambda=-0.5$, (the Fausto Galetto estimate of $\lambda$ ) } \\
\hline Source & SS & df & MS & Fe & $\mathbf{F}^{*}$ & Sig \\
\hline Total & 0.227957 & 40 & $\alpha=$ & 0.1 & & \\
\hline mean & 0.220817 & 1 & & & & \\
\hline Corr_Tot & 0.007040 & 39 & & & & \\
\hline d & 0.002057 & 3 & 0.000686 & 233.02 & 2.29 & * \\
\hline$\theta$ & 0.004888 & 7 & 0.000698 & 237.27 & 1.94 & * \\
\hline$d_{L} \theta_{L}$ & 0.000015 & 1 & 0.000015 & 5.02 & 2.89 & * \\
\hline Residual_GAL & 0.000082 & 28 & 0.0000029 & & & \\
\hline$d_{L}$ & 0.0020023 & 1 & 0.0020023 & 680.38 & 2.89 & * \\
\hline$d_{Q}$ & 0.0000142 & 1 & 0.0000142 & 4.82 & 2.89 & * \\
\hline$\theta_{\mathrm{L}}$ & 0.0047316 & 1 & 0.0047316 & 1607.77 & 2.89 & * \\
\hline$\theta_{\mathrm{Q}}$ & 0.0001257 & 1 & 0.0001257 & 42.72 & 2.89 & * \\
\hline
\end{tabular}

NOTICE (and meditate) that we used 40 data (for the ANOVA) to make the analysis "balanced"... to be compared with the one with $\lambda=0.5$.

The 34 transformed data (from the graphs, table 6) have a value AD (Anderson Darling)=0.185; therefore the transformed data with $\lambda=-0.5$ [Galetto Fausto] are "more normal" than the transformed data with $\lambda=0.5$ [QEG].

NOTICE (and meditate):

from table 8, we see clearly that the Quadratic effect $\mathrm{d}_{\mathrm{Q}}$ of the distance and the Linear effect $\theta_{\mathrm{L}}$ of the angle are very important. These points are completely missed by QEG!

Let's see now the transformation with $\lambda=0.17$ :

Table 9. ANOVA with the data recovered from the graphs and transformed with $\lambda=0.17$.

\begin{tabular}{|c|c|c|c|c|c|c|}
\hline \multicolumn{7}{|c|}{ ANOVA of the data transformed (of curves) with $\lambda=0.17$} \\
\hline Source & SS & df & MS & Fc & $F^{*}$ & Sign \\
\hline Total & 238.86938 & 40 & $\alpha=$ & 0.1 & & \\
\hline mean & 237.91329 & 1 & & & & \\
\hline Corrected Tot & 0.9560838 & 39 & & & & \\
\hline d & 0.2556849 & 3 & 0.0852283 & 186.85 & 2.29 & $*$ \\
\hline$\theta$ & 0.6858521 & 7 & 0.0979788 & 214.81 & 1.94 & $*$ \\
\hline$d_{L} \theta_{L}$ & 0.0017752 & 1 & 0.0017752 & 3.89 & 2.89 & $*$ \\
\hline Residual GAL & 0.0127715 & 28 & 0.0004561 & & & \\
\hline$d_{L}$ & 0.2500331 & 1 & 0.2500331 & 548.17 & 2.89 & $*$ \\
\hline $\mathrm{d}_{\mathrm{Q}}$ & 0.0005219 & 1 & 0.0005219 & 1.14 & 2.89 & \\
\hline$\theta_{\mathrm{L}}$ & 0.6469186 & 1 & 0.6469186 & 1418.29 & 2.89 & * \\
\hline$\theta_{\mathrm{Q}}$ & 0.0358113 & 1 & 0.035811 & 78.51 & 2.89 & * \\
\hline
\end{tabular}

NOTICE that we used 40 data (for the ANOVA) to make the analysis "balanced"... to be compared with those with $\lambda=0.5$ and $\lambda=-0.5$.

The 34 transformed data (from the graphs, table 6) have a value $\mathrm{AD}$ (Anderson Darling) $=0.256$; therefore the transformed data with $\lambda=-0.5$ [Galetto Fausto] are "more normal" than the transformed data with $\lambda=0.17$ [QEG].
NOTICE (and meditate): from table 9, we see clearly that the Linear effect $\theta_{\mathrm{L}}$ of the angle is very important: this point is completely missed by QEG!

NOTICE (and meditate): the Regression formula 7.6 (found 
by QEG)

TOF-Error $=84.6+0.0207 \mathrm{~d}+0.0314 \theta^{2}+0.000336 \mathrm{~d} \theta$

is unsuitable for ««correcting the systematic error in TOF measurements.m!»

We can try to transform, again, the transformed data $\{34$ data with $\lambda=0.5$ [QEG], with $\lambda=-0.5$ [Fausto Galetto] and with $\lambda=0$ [Fausto Galetto $]$; we find the following values $\lambda^{\prime}=-1$ for the transformed data with $\lambda=0.5$ [QEG], $\lambda^{\prime}=1$ for the transformed data with $\lambda=-0.5$ [Fausto Galetto] and $\lambda^{\prime}=-2$ for the transformed data with $\lambda=0$ [Fausto Galetto] and values $\lambda^{\prime}=-2$ for the transformed data with $\lambda=0.17$ [QEG]; therefore we confirm that the most suitable transformation is the one with $\lambda=-0.5$ ! (it depends on the 34 data from the graphs)

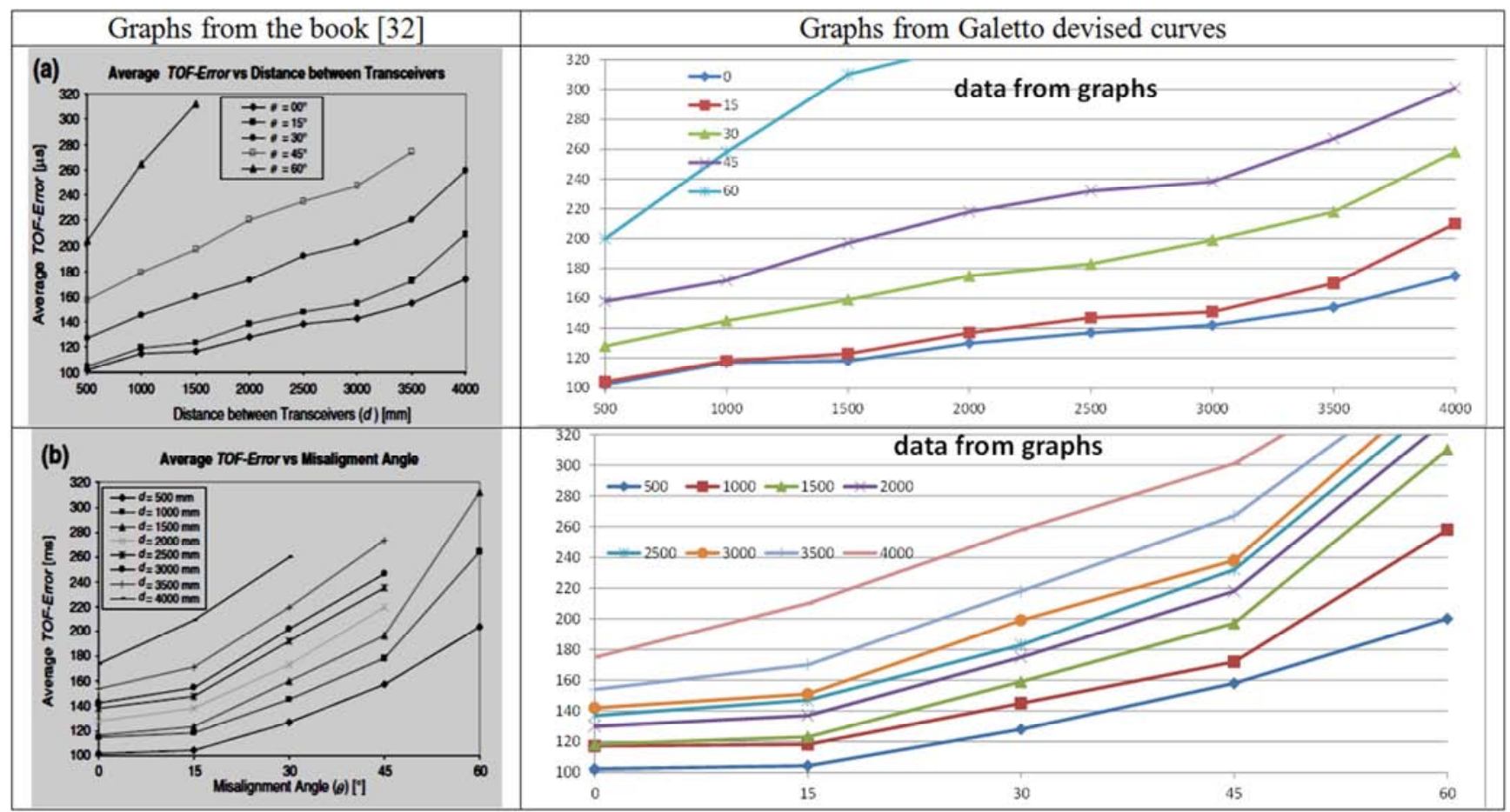

Figure 16. Comparison of the curves (the figure refers to all the 4 parts).

IF we have had the original data we could have done much better....

\section{Analysis of the Experiments Carried out, Using SPQR and Response Surface Methodology (RSM)}

To have a better insight of the results, using only the 34 data of the graphs, we use now the Response Surface Method (RSM), which is nothing different from the G-Method applied to the data in the table 6 .

Using the orthogonal polynomials versus $\theta$, for each disalignment angle, we find (estimate) the regression coefficients $b_{0}, b_{1}, b_{2}$ : they are uncorrelated because we used the orthogonal polynomials! Therefore we can easily find the Confidence Intervals (with 99\% CL). The standard deviation was taken from the QEG ANOVA...

Table 10 provides the confidence intervals.

Since the regression coefficients $b_{0}, b_{1}, b_{2}$ depend on the angle we show their relationship in the figures 17, 18, 19.

Table 10. Estimates of the regression coefficients and Confidence Intervals.

\begin{tabular}{llllllllll}
\hline angle & $\mathbf{b}_{\mathbf{0}}=$ mean & $\mathbf{L C L}$ & $\mathbf{U C L}$ & $\mathbf{b}_{\mathbf{1}}$ & $\mathbf{L C L}$ & $\mathbf{U C L}$ & $\mathbf{b}_{\mathbf{2}}$ & $\mathbf{L C L}$ & $\mathbf{U C L}$ \\
\hline 0 & 134.38 & 132.796 & 135.954 & 0.018452 & 0.017074 & 0.019831 & 0.000002262 & 0.000000884 & 0.000003640 \\
15 & 145.00 & 143.421 & 146.579 & 0.026095 & 0.024717 & 0.027474 & 0.000005810 & 0.000004431 & 0.000007188 \\
30 & 183.13 & 181.546 & 184.704 & 0.033405 & 0.032026 & 0.034783 & 0.000004786 & 0.000003407 & 0.000006164 \\
45 & 211.71 & 210.026 & 213.402 & 0.035286 & 0.033598 & 0.036974 & -0.000001619 & -0.000003568 & 0.000000330 \\
60 & 256.00 & 253.421 & 258.579 & 0.110000 & 0.103683 & 0.116317 & -0.000012000 & -0.000033881 & 0.000009881 \\
\hline
\end{tabular}




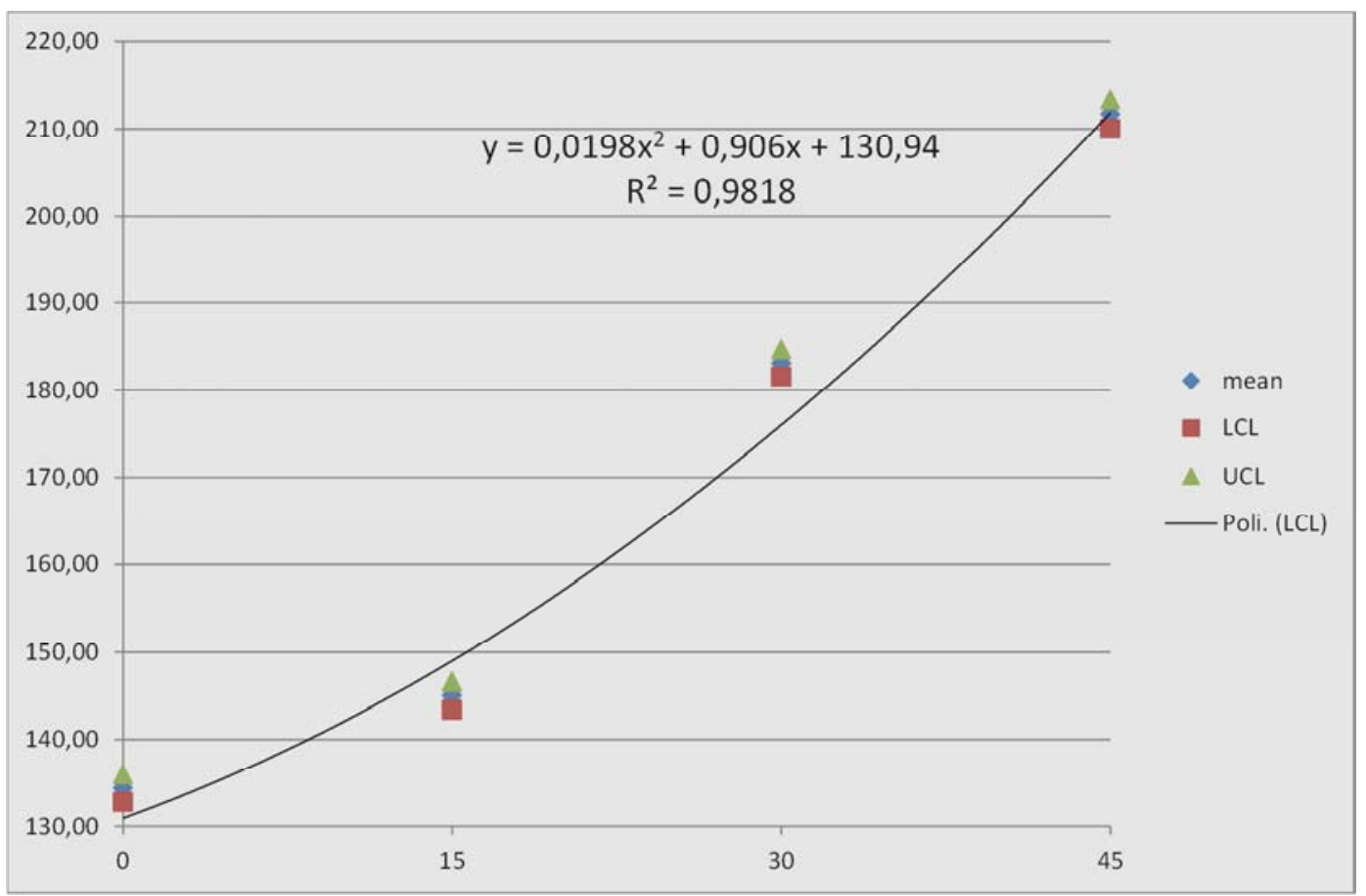

Figure 17. Regression coefficient $b_{0}\left(b_{0}=\right.$ mean effect of the angle).

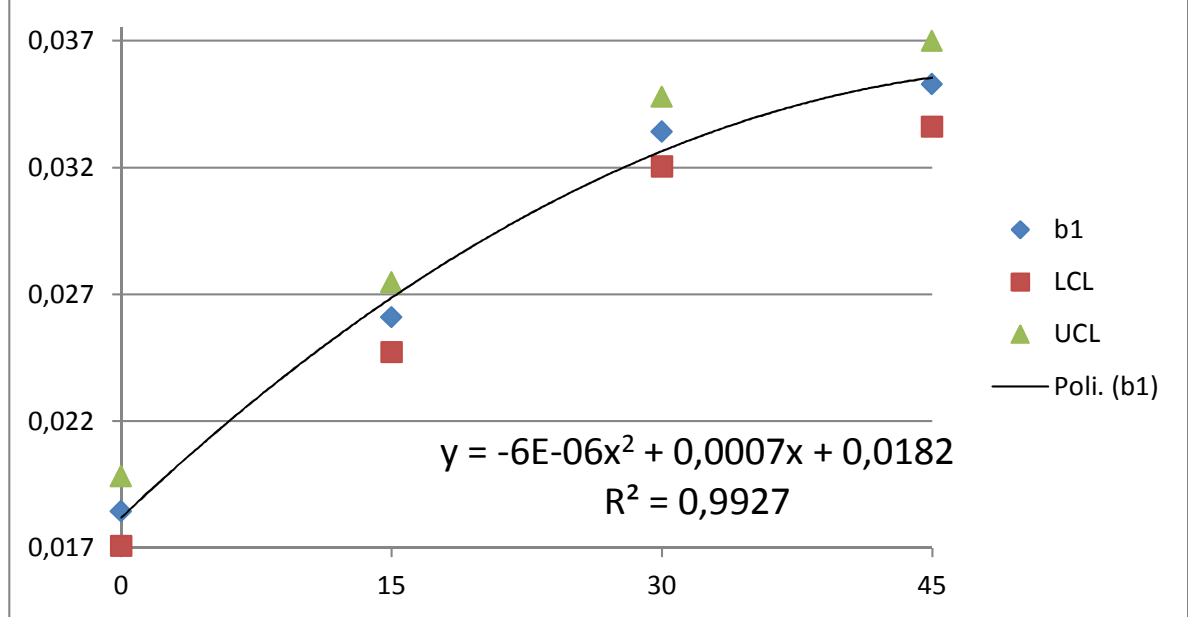

Figure 18. Regression coefficient $b_{1}\left(b_{1}=\right.$ linear effect of the angle).

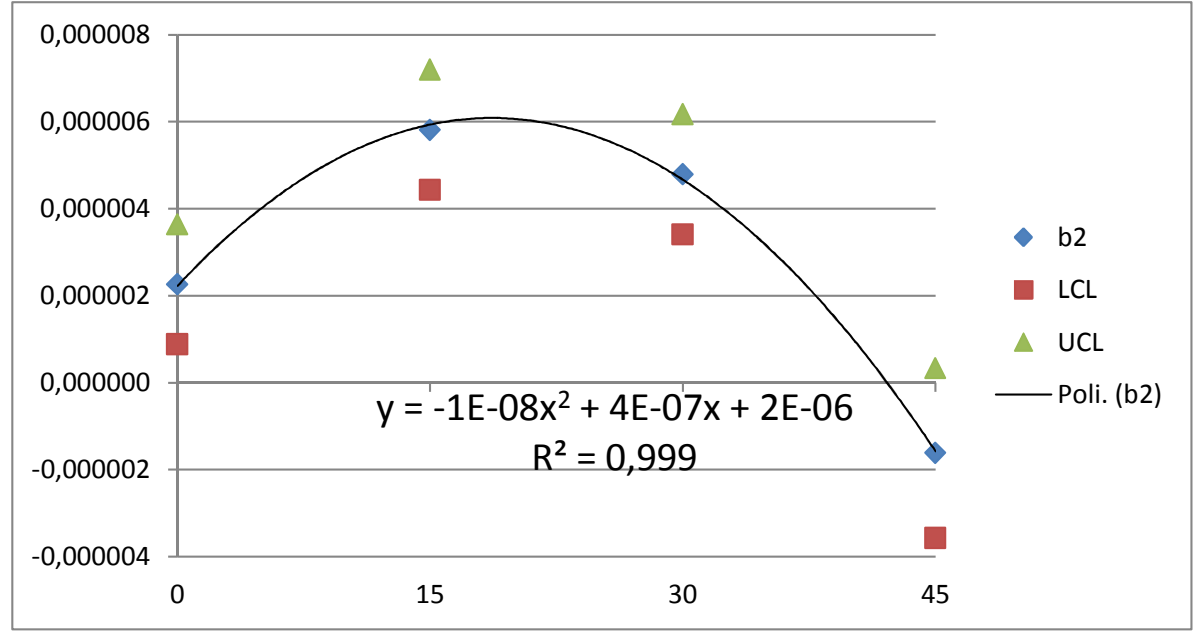

Figure 19. Regression coefficient $b_{2}\left(b_{2}=\right.$ quadratic effect of the angle). 
Graphing these findings it is clear that there are significantly different estimates of constant $\left(b_{0}=\right.$ mean $)$, linear $\left(b_{1}\right)$ and quadratic $\left(b_{2}\right)$ effects of the angle! Moreover, $b_{0}, b_{1}$ and $b_{2}$ vary parabolically with the angle $\theta$ !

This point was missed by QEG! [professors... graduated with "magna cum laude"!]

Therefore it is absolutely unwise to pretend that a unique formula, such the (7.6), could give the response variable (the graphs of QEG were very clear on that, but the professors did not realise that!!!).

Minitab was of no help on that: GIGO!

Making a sound regression of the data of the graphs (using only the 34 collected data from the graphs) one finds Table 11.

Acting as QEG did one finds that the "Mallows' $\mathrm{C}_{\mathrm{p}}$ " is 9, and therefore the coefficients of Table 8 must be used and not the ones found by QEG!!!

See the table 9 and compare it with... the excerpt from the book: all the regression variables $\mathrm{d}, \mathrm{d}^{2}, \mathrm{~d}^{3}, \mathrm{~d}^{4}, \theta, \theta^{2}, \theta^{3}, \mathrm{~d} \theta$ are important for describing the measures of the measurand.

Therefore the QEG equation

$$
\mathrm{TOF}_{\text {Error }}=84.6+0.0207 \mathrm{~d}+0.0314 \theta^{2}+0.000336 \mathrm{~d} \theta(7.6)
$$

is quite unsuitable to provide what is needed (as we said before when we transformed the data)!

The Response Surface is given in the graph of figure 21; on the base you can see the contour lines.

Table 11. Coefficients of the regression variables.

\begin{tabular}{cccccccccc}
\hline variable & mean & $\mathbf{d}$ & $\mathbf{d}^{\mathbf{2}}$ & $\mathbf{d}^{\mathbf{3}}$ & $\mathbf{d}^{\mathbf{4}}$ & $\boldsymbol{\theta}$ & $\boldsymbol{\theta}^{2}$ & $\boldsymbol{\theta}^{\mathbf{3}}$ & $\mathbf{d} \boldsymbol{\theta}$ \\
\hline estimate & 82.319 & 0.0358 & 0.00000506 & $-8.943 \mathrm{E}-09$ & $1.741 \mathrm{E}-12$ & -0.429 & 0.00569 & 0.000513 & 0.000560 \\
\hline
\end{tabular}

Table 12. Best regression variables according to Fausto Galetto.

\begin{tabular}{|c|c|c|c|c|c|c|c|c|c|c|}
\hline variables & $\operatorname{adj} R^{2}$ & Mallows' $\mathbf{C}_{p}$ & d & $d^{2}$ & $d^{3}$ & $d^{4}$ & $\theta$ & $\theta^{2}$ & $\theta^{3}$ & $d \theta$ \\
\hline 7 & 96.5 & 7 & $X$ & & $\mathrm{X}$ & $\mathrm{X}$ & $\mathrm{X}$ & $\mathrm{X}$ & $\mathrm{X}$ & $\mathrm{X}$ \\
\hline 7 & 96.5 & 7 & $\mathrm{X}$ & $\mathrm{X}$ & $\mathrm{X}$ & $\mathrm{X}$ & $\mathrm{X}$ & & $\mathrm{X}$ & $\mathrm{X}$ \\
\hline 8 & 96.3 & 9 & $X$ & $X$ & $\mathrm{X}$ & $\mathrm{X}$ & $X$ & $X$ & $\mathrm{X}$ & $\mathrm{X}$ \\
\hline
\end{tabular}

... the excerpt from the book

\section{Best Subsets Regression:}

Average TOF-Error versus $\boldsymbol{d}, \theta, \boldsymbol{d}^{2}, \theta^{2}$ and $\boldsymbol{d} \cdot \theta$
Vars $R^{2}$
$\mathrm{R}^{2}$ (adj) Mallows' $C p$
$\left(K_{2}\right)\left(K_{3}\right)\left(K_{4}\right)\left(K_{5}\right)\left(K_{4}\right)$
395.0
94.5
$4.3 \quad 11.785$
d $\theta \quad d^{2} \theta^{2} d \cdot \theta$

Figure 20. Best Regression variables according to the QEG [from which they chose formula (7.6)].

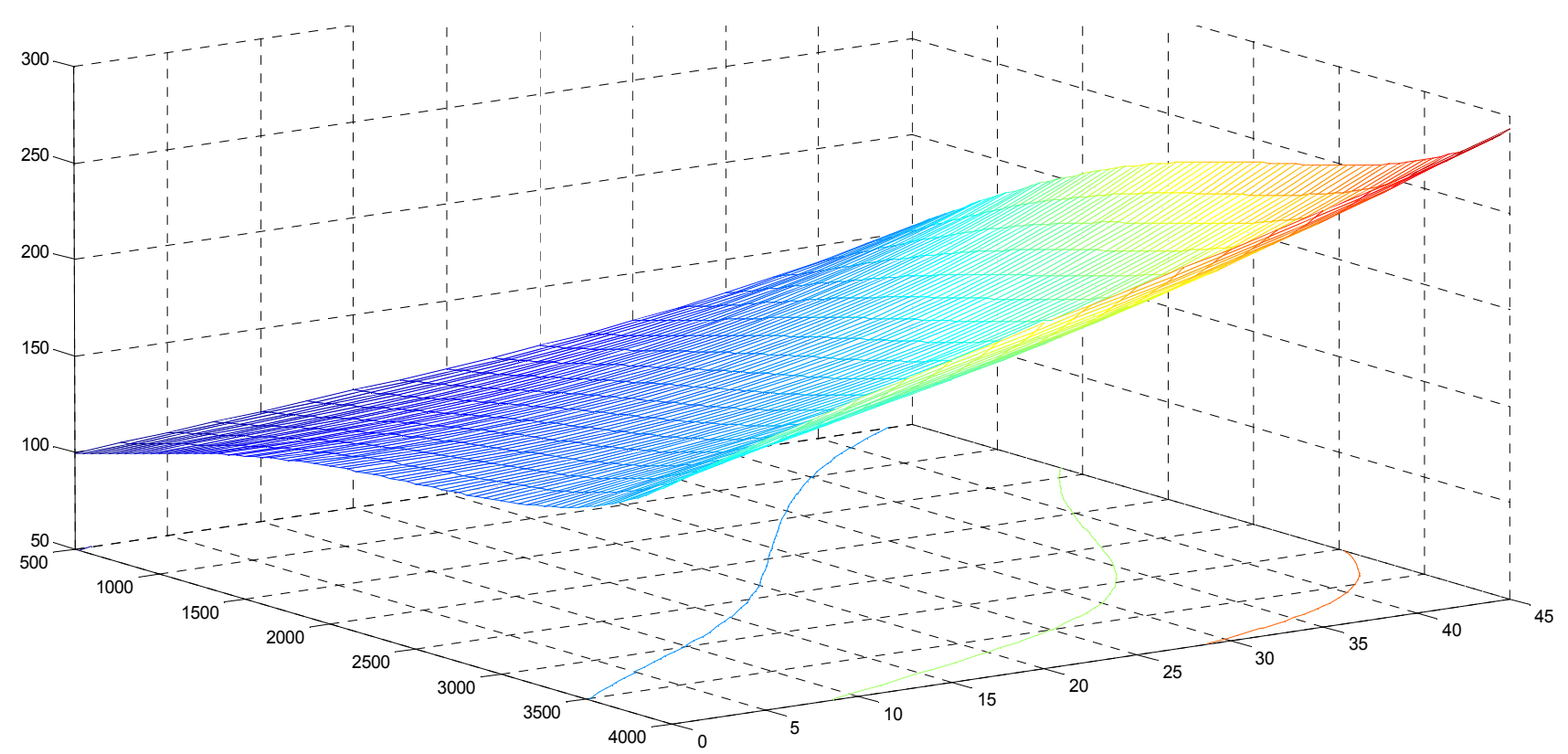




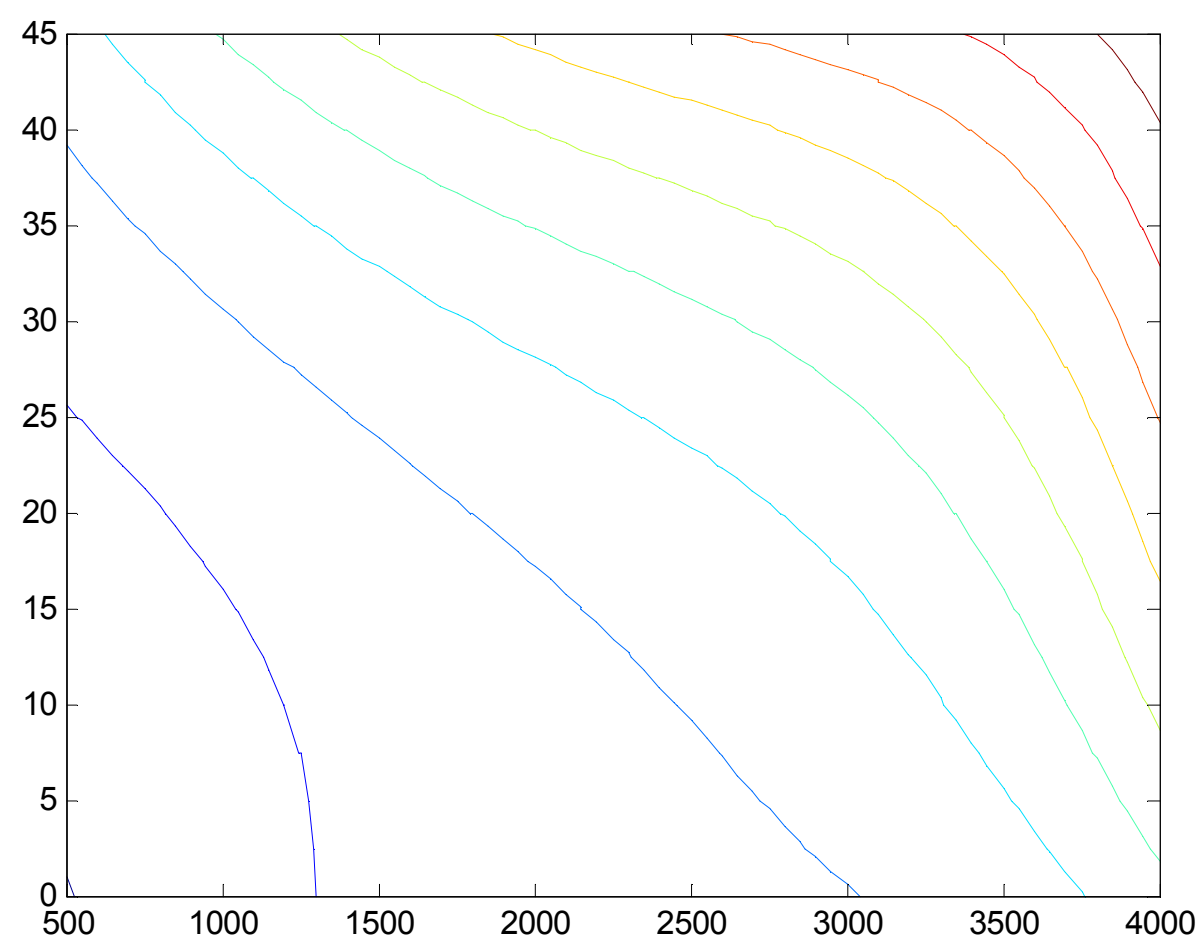

Figure 21. Response Surface according to the QEG Regression, on the left; contour lines on the right.

The author thinks that the reader of the paper should agree that the QEG statement "The model fits well with experimental data." is false.

In the author's opinion it would be better, on the contrary, to put SPQR in action!

"Quality of Quality Methods is important" (F. Galetto), as

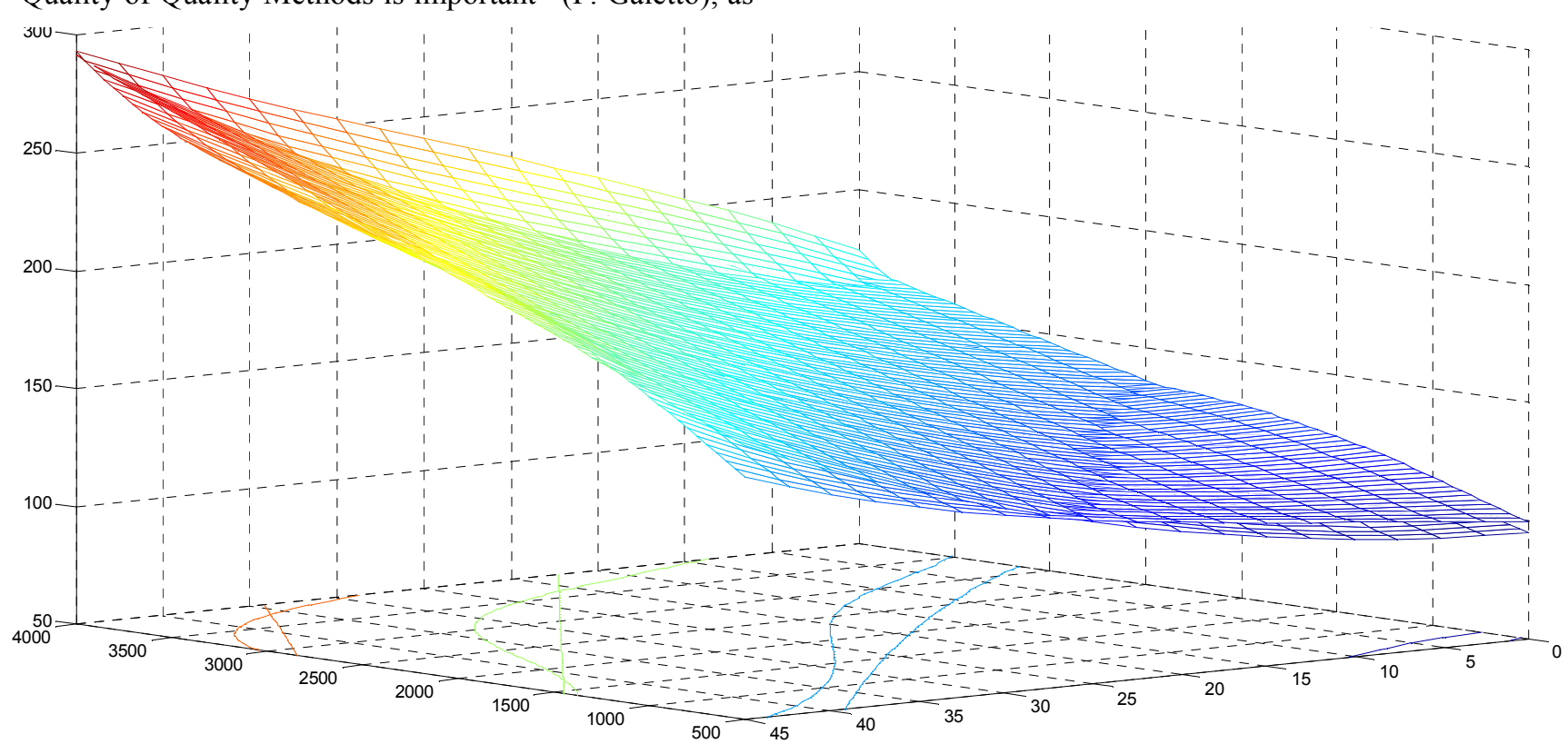

it was appreciated by J. Juran at Vienna EOQC Conference! To compare the two surfaces we did the $1^{\text {st }}$ following graph; in the $2^{\text {nd }}$ where you see a different view of the previous surface; the difference is more evident with the contour lines on the base. 


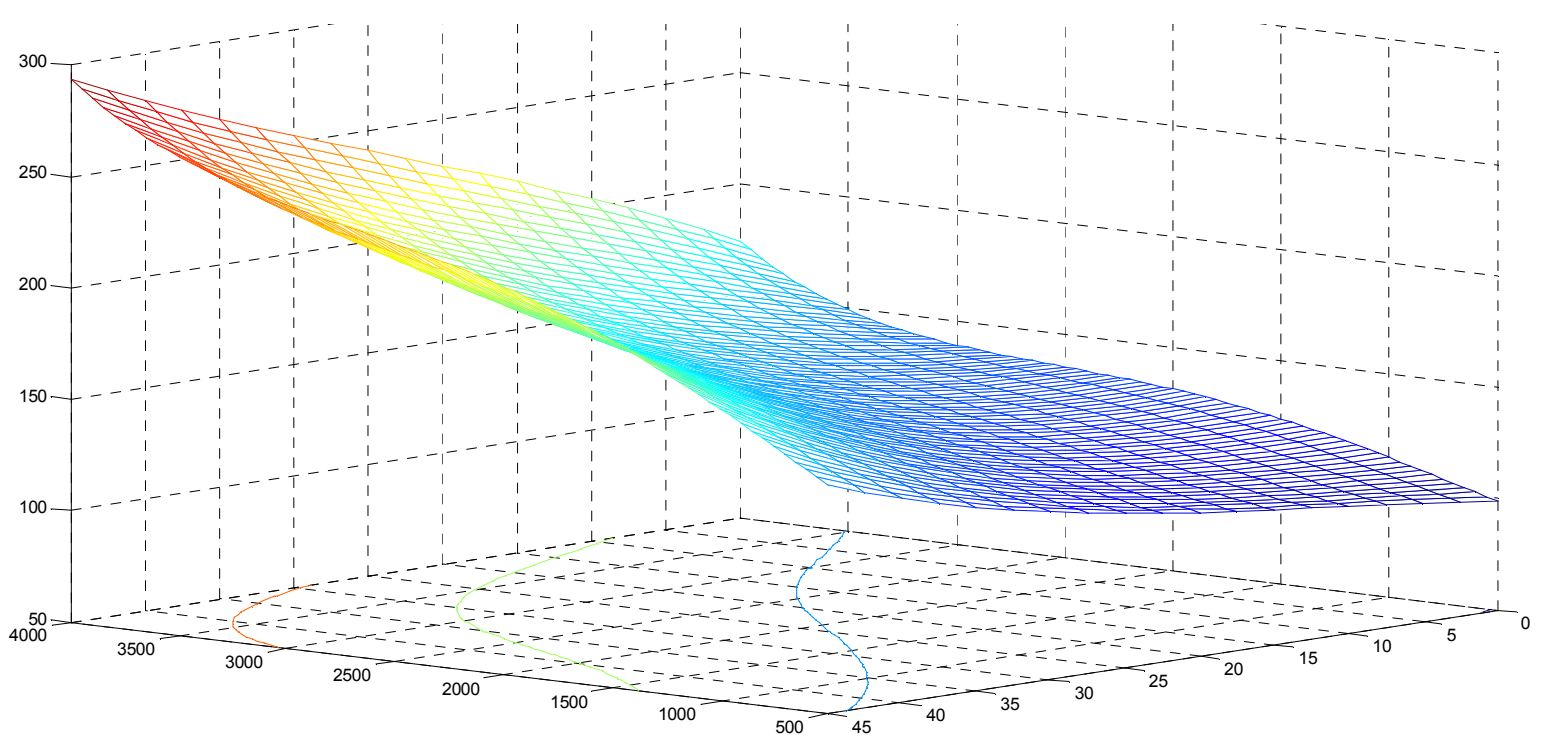

Figure 22a. Response Surface of the two formulae ( $Q E G$ and F. Galetto), on the left; $Q E G$ on the right.

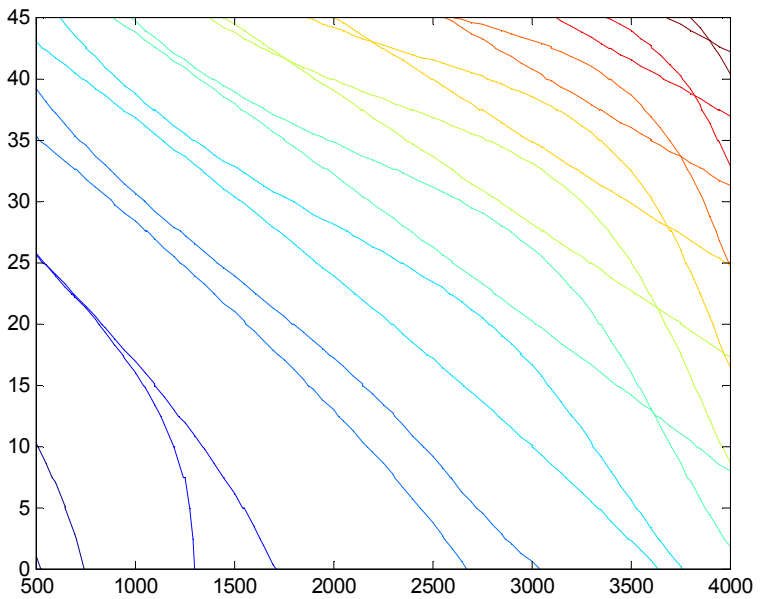

Figure 22b. Contour lines of the two formulae ( $Q E G$ and $F$. Galetto).

It is evident, as it must be, that the two formulae provide different estimates of the $\mathrm{TOF}_{\text {Error; }}$; therefore... see table 13.

Since we do not have the original data we cannot compare the two regression models directly.

We can only use the data from the graphs.

Making the ANOVA for the models we get the MS of Residuals; their ratio are given in the Table 13 Comparison of TOF $F_{\text {Error }}$ models: QEG versus Fausto Galetto.

From Table 13 we see clearly that the two models are Significantly Different, at $0.5 \%$ significance level.

Table 13. Comparison of TOF Error models: $Q E G$ versus Fausto Galetto.

\begin{tabular}{lrrrr}
\hline & df & MS_Residual & ratio & F*(0.5\%) \\
\hline QEG model & 30 & 181.00 & 3.267 & 2.819 \\
Fausto Galetto model & 25 & 54.40 & & \\
\hline
\end{tabular}

The following figure compares graphically the various RSM via the direct regression and the four regressions-antistransformed of the transformed data...

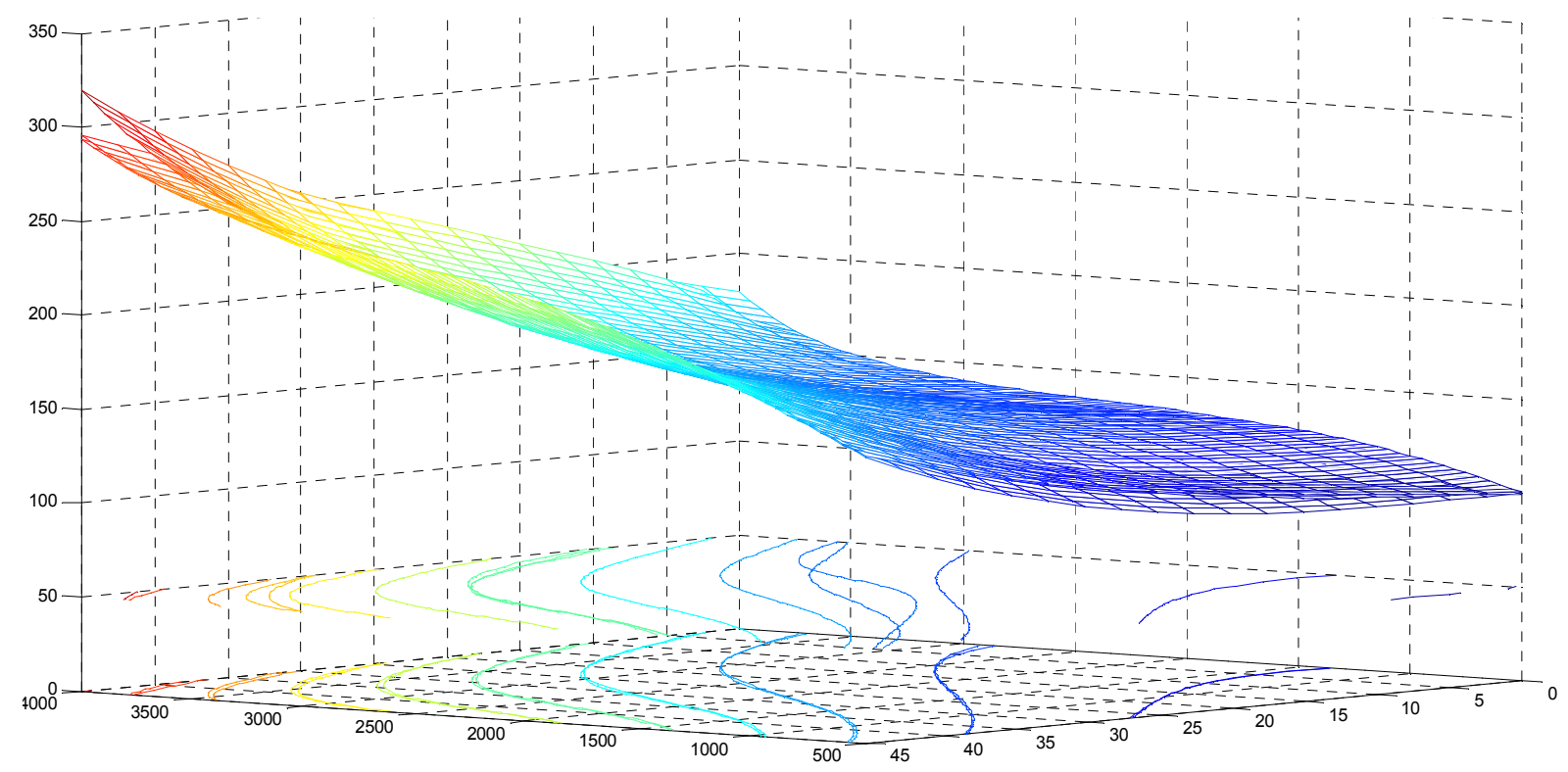

Figure 23. Response Surfaces Comparison by transforming the data for regression and later anti_transforming. 
Any sensible scholar does have to conclude that the QEG equation

$$
\mathrm{TOF}_{\text {Error }}=84.6+0.0207 \mathrm{~d}+0.0314 \theta^{2}+0.000336 \mathrm{~d} \theta(7.6)
$$

is quite unsuitable to provide what is needed...

Therefore the negative considerations [1, 2] on the Open Access Publishers are valid also for other publishers: see several F. Galetto papers e.g, "Comment on: 'New Practical Bayes Estimators for the 2-parameters Weibull distribution, IEEE Transactions on Reliability vol. 37, 1988”, “(1989) Quality of methods for quality is important, EOQC Conference, Vienna”, “(1990) Basic and managerial concerns on Taguchi Methods, ISATA, Florence", "Managerial Issues for Design of Experiments, $4^{\text {th }}$ AMST 96, Udine, 1996", "Quality Education on Quality for Future Managers, $1^{\text {st }}$ Conference on TQM for HEI (Higher Education Institutions), Tolone, 1998", "Quality Function Deployment, Some Managerial Concerns, AITEM99, Brescia, 1999”, "Quality Education for Professors teaching Quality to Future Managers, $3^{\text {rd }}$ Conf. on TQM for HEI, Derby, UK, 2000", "Quality, Bayes Methods and Control Charts, $2^{\text {nd }}$ ICME 2000 Conference, Capri, 2000", "Looking for Quality in "quality books", $4^{\text {th }}$ Conf. on TQM for HEI, Mons, Belgium, 2001", Galetto, F., Quality and Control Carts: Managerial assessment during Product Development and Production Process, AT\&T (Society of Automotive Engineers), Barcelona, 200", "Fuzzy Logic and Control Charts, $3^{\text {rd }}$ ICME 2002 Conference, Ischia, 2002", "Analysis of "new" control charts for Quality assessment, $5^{\text {th }}$ Conf. on TQM for HEI, Lisbon, Portugal, 2002", "Quality and "quality magazines", $6{ }^{\text {th }}$ Conf. on TQM for HEI, Oviedo, Spain, 2003", "Statistics for Quality and "quality magazines", $5^{\text {th }}$ ENBIS, Newcastle, 2005", "Service Quality: Fuzzy Logic and Yager Method; a scientific analysis, IFIP TC 7, Politecnico di Torino, 2005", "Fuzzy Logic and Quality Control: a scientific analysis, IPSI 2006, Amalfi, 2006", "Does "Peer Review" assure Quality of papers and
Education?, $8^{\text {th }}$ Conf. on TQM for HEI, Paisley, Scotland, 2006", "The Pentalogy, VIPSI, Belgrado, 2009", "The Pentalogy Beyond, $9^{\text {th }}$ Conf. on TQM for HEI, Verona, 2010".

\section{Open Access Versus Non-open Access}

We ended the previous section with the statement "Therefore the negative considerations $[1,2]$ on the Open Access Publishers are valid also for other publishers: see several F. Galetto papers....".

We prove here that Non-Open Access Publishers have the same problems of the OAP: the cause is the incompetence of the authors and of the Peer Reviewers (Referees). All the F. Galetto papers proved that for many years (see those in $\S 7$ ).

Here we consider only two of them: both are related to the Quality Engineering Group of Turin Politecnico... I invited them many times to be scientific... without success!

According to prof. F. Franceschini [a member of QEG!], papers published in Quality Magazines are, by definition, good papers: many times that is not true.

The papers considered were found by chance while looking for other papers for other ideas.

Let's stand-back a bit and meditate, starting from a managerial point of view, using published documents (found in magazines used by managers and professionals, and suggested to students), and analysing them using the SPQR Principle.

We start with the paper "Learning curves and p-charts for a preliminary estimation of asymptotic performances of a manufacturing process" [Total Quality Management Franceschini F. (2002)]. Franceschini suggests [as the QEG does] Montgomery book to his students and the data (non-conformity) he uses in the paper are from the Montgomery book; 30 samples (with 50 sample size) and 24 samples are used: [surely Total Quality Management is a journal of a Non-Open Access Publisher]

Table 14. Data from "Learning curves and p-charts for a preliminary estimation of asymptotic performances of a manufacturing process" [Total Quality Management Franceschini $F$. (2002)] (nc=number of nonconforming products, $p=$ proportion of nonconforming products).

\begin{tabular}{|c|c|c|c|c|c|c|c|c|c|c|c|c|c|c|c|c|c|}
\hline \multicolumn{18}{|c|}{ first 30 samples for the Control Chart Setting } \\
\hline sample & nc & $\mathbf{p}$ & sample & nc & $\mathbf{p}$ & sample & nc & $\mathbf{p}$ & sample & nc & $\mathbf{p}$ & sample & nc & $\mathbf{p}$ & sample & nc & $\mathbf{p}$ \\
\hline 1 & 12 & 0.24 & 2 & 15 & 0.30 & 3 & 8 & 0.16 & 4 & 10 & 0.20 & 5 & 4 & 0.08 & 6 & 7 & 0.14 \\
\hline 7 & 16 & 0.32 & 8 & 9 & 0.18 & 9 & 14 & 0.28 & 10 & 10 & 0.20 & 11 & 5 & 0.10 & 12 & 6 & 0.12 \\
\hline 13 & 17 & 0.34 & 14 & 12 & 0.24 & 15 & 22 & 0.44 & 16 & 8 & 0.16 & 17 & 10 & 0.20 & 18 & 5 & 0.10 \\
\hline 19 & 13 & 0.26 & 20 & 11 & 0.22 & 21 & 20 & 0.40 & 22 & 18 & 0.36 & 23 & 24 & 0.48 & 24 & 15 & 0.30 \\
\hline 25 & 9 & 0.18 & 26 & 12 & 0.24 & 27 & 7 & 0.14 & 28 & 13 & 0.26 & 29 & 9 & 0.18 & 30 & 6 & 0.12 \\
\hline
\end{tabular}

\begin{tabular}{|c|c|c|c|c|c|c|c|c|c|c|c|c|c|c|c|c|c|}
\hline sample & nc & $\mathbf{p}$ & sample & nc & $\mathbf{p}$ & sample & nc & $\mathbf{p}$ & sample & nc & $\mathbf{p}$ & sample & nc & $\mathbf{p}$ & sample & nc & $\mathbf{p}$ \\
\hline 1 & 9 & 0.18 & 2 & 6 & 0.12 & 3 & 12 & 0.24 & 4 & 5 & 0.10 & 5 & 6 & 0.12 & 6 & 4 & 0.08 \\
\hline 7 & 6 & 0.12 & 8 & 3 & 0.06 & 9 & 7 & 0.14 & 10 & 6 & 0.12 & 11 & 2 & 0.04 & 12 & 4 & 0.08 \\
\hline 13 & 3 & 0.06 & 14 & 6 & 0.12 & 15 & 5 & 0.10 & 16 & 4 & 0.08 & 17 & 8 & 0.16 & 18 & 5 & 0.10 \\
\hline 19 & 6 & 0.12 & 20 & 7 & 0.14 & 21 & 5 & 0.10 & 22 & 6 & 0.12 & 23 & 3 & 0.06 & 24 & 5 & 0.10 \\
\hline
\end{tabular}


Considering all the samples one finds the following Control Chart

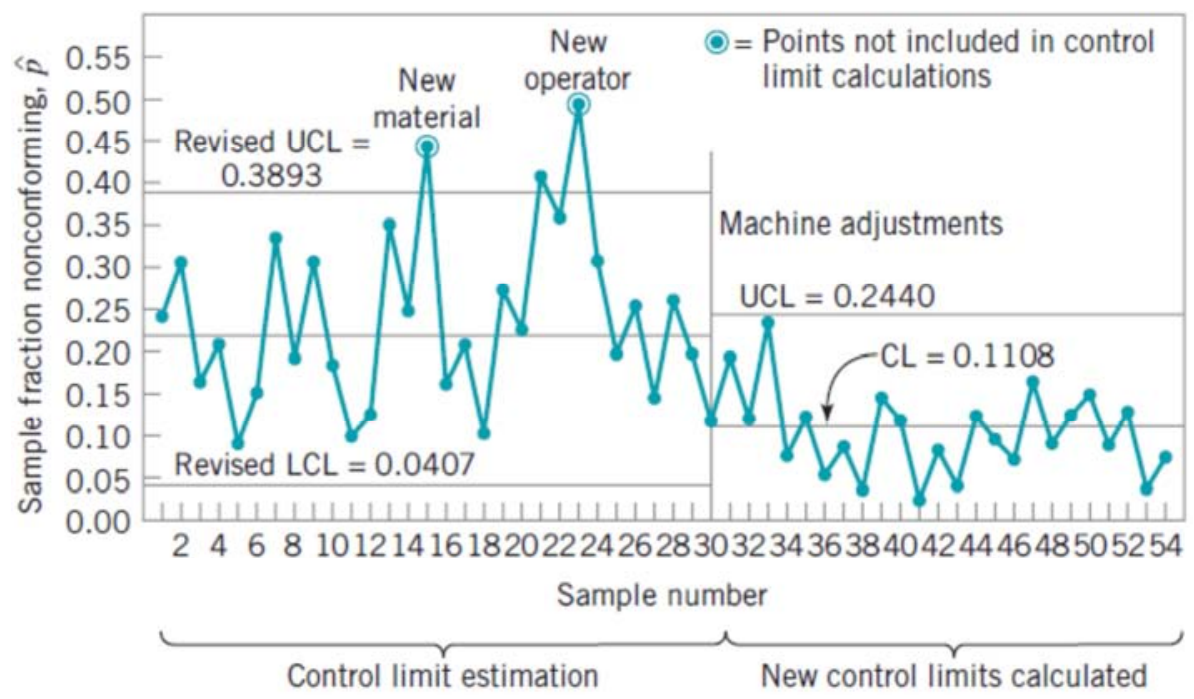

Figure 24. Control Chart of the data of table 14.

The QEG member F. Franceschini, being cheated by the data and by the graph, decided to interpolate a curve whose equation was $\mathrm{p}=\mathrm{a} / \mathrm{t}+\mathrm{c}$; the coefficients are estimated by the formulae

$$
\hat{a}=\frac{\overline{p_{1}}-\overline{p_{2}}}{1 / \overline{t_{1}}-1 / \overline{t_{2}}}(1) \text { and } \hat{c}=\overline{p_{1}}-\hat{a} / \overline{t_{1}}
$$

with variance

$$
\begin{gathered}
\sigma_{a}^{2}=\left[\overline{t_{1}} \overline{t_{2}} /\left(\overline{t_{2}}-\overline{t_{1}}\right)\right]^{2}\left(\sigma_{p 1}^{2}+\sigma_{p 2}^{2}\right) \\
\sigma_{c}^{2}=\left[\overline{\overline{t_{2}}}\right]_{\overline{t_{2}}-\overline{t_{1}}}^{2} \sigma_{p 1}^{2}+\left[\overline{\overline{t_{1}}}\right]^{2} \sigma_{p 2}^{2}
\end{gathered}
$$

The "barred" values with suffix 1 are the single values (means) computed from the $1^{\text {st }} 30$ samples, while the "barred" values with suffix 2 are the single values (means) computed from the $2^{\text {nd }} 24$ samples!!!! Therefore we have two values for the proportion $\mathrm{p}$ (the mean of the nonconformity proportion of the $1^{\text {st }} 30$ samples and the mean of the nonconformity proportion of the $2^{\text {nd }} 24$ samples) and two mean values for the time $t$ (of the $1^{\text {st }} 30$ samples and of the $2^{\text {nd }} 24$ samples): the estimates of the parameters a and $c$ are easily found. Since there are 30 proportions $p_{i}$ for the $1^{\text {st }} 30$ samples and 24 proportions $p_{i}$ for the $2^{\text {nd }} 24$ samples we can accept that the two "estimators" of two mean proportions are normally distributed.

From that any sensible researcher or scholar (who knows the Basics of Statistics) can compute the Confidence Intervals (CI) of the parameters estimates.

Unfortunately, the QEG member F. Franceschini did not compute them!

IF he had computed the CI (assuming normal distribution) the QEG member F. Franceschini would have found that the value 0 belongs to them: therefore, according to Franceschini formulae, the parameters estimates are not significantly different from $0 ! ! !$

Therefore, pretending that the formula $\mathrm{p}=\mathrm{a} / \mathrm{t}+\mathrm{c}$ provides the asymptotic defectiveness is nonsense: the QEG member F. Franceschini did not realise that.... Look at the figure with 40 more samples... that show QEG nonsense!!!

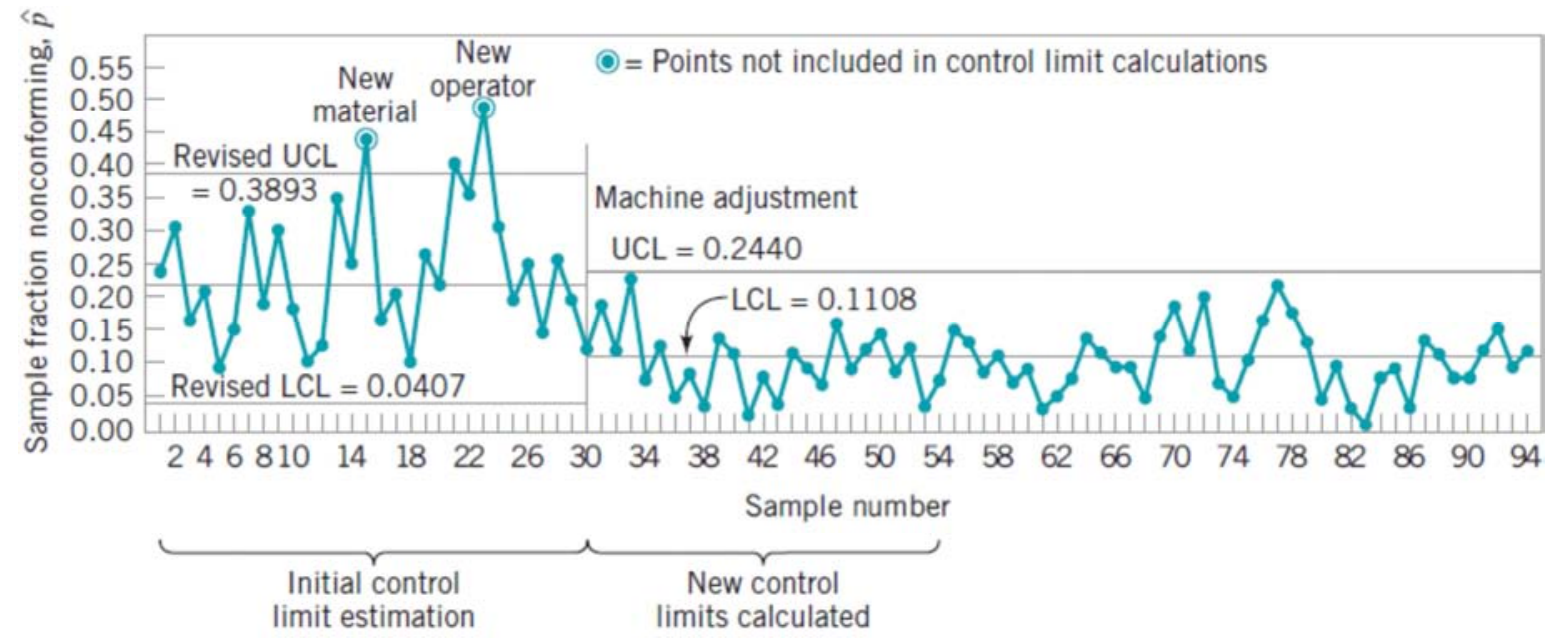

Figure 25. Control Chart of the data of table 14 and new data [40 new samples (given in Montgomery book)]. 
The author thinks that the reader of the paper should agree that the QEG fellow was wrong!

The referee of the paper could not find what students can find. If you look at the future data (given in Montgomery book) you find different results ... [see the previous figure 25]

In the author's opinion it would be better, on the contrary, to put SPQR in action!

"Quality of Quality Methods is important" (F. Galetto), as it was appreciated by J. Juran at Vienna EOQC Conference!

Since Total Quality Management is surely a journal of a Non-Open Access Publisher it is clear that Quality of papers depends on the authors and not on the publishers.

QEG member have been very active on Control Charts; they invented firstly the "Qualitometro I method (1998) ... in order to evaluate and check on-line service quality" because "there is now a strong need for proper evaluation tools", [Franceschini, Romano, Rossetto, 1998-1999-2000]. Later (1999 and 2000) it was presented and discussed " $a$ new proposal for data processing that enhances elaboration capabilities of Qualitometro I. This new procedure, named Qualitometro II, is able to manage information given by customers on linguistic scales, without any arbitrary and artificial conversion of collected data. Collecting and treating data by means of the Qualitometro II eases this process providing a method for performing elaboration closer to customers fuzzy thoughts. ... Qualitometro II method can be interpreted as a Group Decision Support Tool for service quality design/redesign ... able to handle information expressed on linguistic scales, without any artificial numeric scalarization." Hence they introduce a "new instrument that can fulfil the formal properties of a linguistic scale and allow for the expression of the variety in the decisional logic of the evaluator. ... The fuzzy operator that is used allows for this flexibility in the decision logic." (underlinement is due to F. Galetto). In 2005 QEG member invented the Qualitometro III method in papers related to "Ordered Samples Control Charts for Ordinal Variables" (Quality and Reliability Engineering International)... They write: "The paper presents a new method for statistical process control when ordinal variables are involved. This is the case of a quality characteristic evaluated by on ordinal scale. The method allows a statistical analysis without exploiting an arbitrary numerical conversion of scale levels and without using the traditional sample synthesis operators (sample mean and variance). It consist of different approach based on the use of a new sample scale obtained by ordering the original variable sample space according to some specific 'dominance criteria' fixed on the basis of the monitored process characteristics. Samples are directly reported on the chart and no distributional shape is assumed for the population (universe) of evaluations".

NOTICE (and meditate): it very interesting to notice that some students of mine, L. Perri (2002), E. Mori (2006) and J. Baucino (2008) found the drawbacks of fuzzy sets in control charts for services and other Control Charts [in books and papers]: using those rules for analysing the process behaviour one can find that they provide at least $20 \%$ out of control events for random data "uniformly distributed" on the scale points: such data must be "in control" by definition!!! (F. Galetto 2002, 2003, 2004, 2005, L. Perri 2002)

It is clear that there is something wrong in the way of using fuzzy sets in control charts for services.

There is not space for showing how much are wrong fuzzy ideas applied to Quality. [see References]

We only mention that those wrong ideas come from Yager (1981) "A new methodology for ordinal multiobjective decision based on fuzzy sets", where he invented a method to avoid the "tyranny of numbers" because "... forcing the decision maker to supply information with greater precision than he is capable of providing. This may lead to incorrect answers...".

Quality Engineering, International Journal Of Production Research and Decision Sciences, Information and Control, Quality and Reliability Engineering International are surely journals published by Non_Open Access Publishers.

Now we see a third case related to the paper [115] "S. El-Ferik and M. Ben-Daya, 2008, Model for imperfect age-based preventive maintenance with age reduction", published in the Journal of the Operational Research Society (2008) 59, $1644-1651$, surely journals published by Non_Open Access Publisher.

S. El-Ferik and M. Ben-Daya wrote [115] "The effect of ageing on the deterioration rate of most repairable systems cannot be ignored. Preventive maintenance (PM) is performed in the hope of restoring fully the performance of these systems. However, in most practical cases, PM activities will be only able to restore part of the performance. Bridging the gap between theory and practice in this area requires realistic modelling of the effect of $P M$ activities on the failure characteristics of maintainable systems. Several sequential PM models have been developed for predetermined PM interval policies but much less effort has been devoted to age-based ones. The purpose of this paper is to develop an age-based model for imperfect PM. The proposed model incorporates adjustment factor in the effective age of the system. The system undergoes PM either at failure or after a predetermined time interval whichever of them occurs first. After a certain number of such PMs, the system is replaced. The problem is to determine both the optimal number of PMs and the optimal PM's schedule that minimize the total longterm expected cost rate. Model analysis relating to the existence and uniqueness of the optimal solutions is provided. Numerical examples are presented to study the sensitivity of the model to different cost function's factors and to illustrate the use of the algorithm."

Fausto Galetto always tried to teach his students to be Scientific (using their own Intelligence) when dealing with Reliability... always warning them to be very careful in order not to be cheated by incompetent authors allowed to publish papers by incompetent referees. A rule always told them was: "IF a new model does not provide known results in known Scientific cases that model is to be considered as not-scientific" (Relativity Theory provides the Newtonian 
Theory when the speed of frames is very low with respect to the light speed c).

The two authors compute wrongly the expected cycle length with the formula

$$
L\left[N,\left\{y_{i}\right\}\right]=\sum_{i=1}^{N} \int_{b_{1-1}}^{y_{i}} y_{i-1} R(t) d t(5)
$$

Any scholar, researcher, student can see that (5) is wrong by reading about the Reliability Integral Theory in the books [105-108]!!! It is clear that (5) is wrong because it provides an expected cycle length bigger than the one of a system with complete renewal at any preventive maintenance!!!

Many papers and books deal with preventive maintenance ONLY in the STEADY State case (i.e. when the "planning horizon is infinite")!

Only Fausto Galetto considered the THEORY of preventive maintenance when the "planning horizon is finite". [105-108]

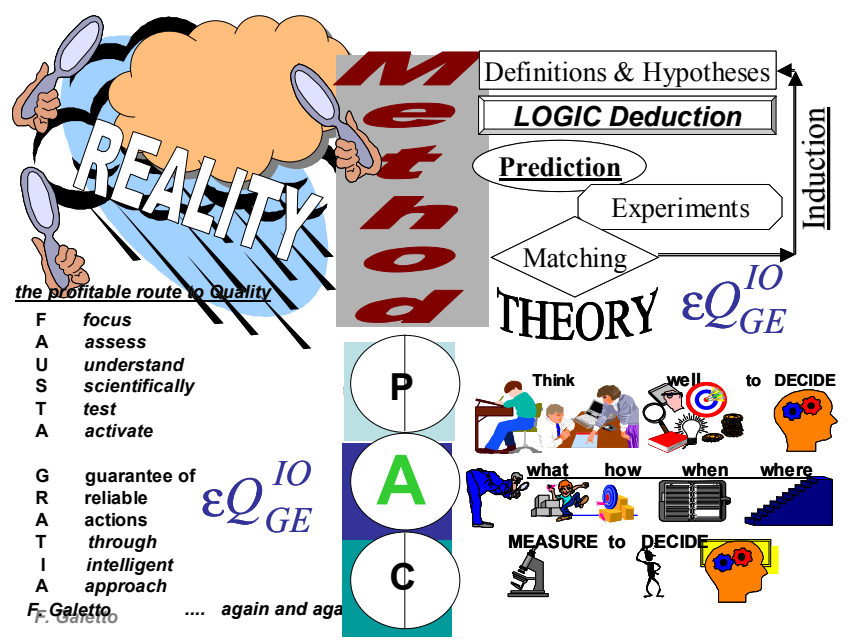

Figure 26. FAUSTA GRATIA for Quality in order to avoid the Disquality.

The difference in the optimised preventive maintenance interval can be very important as the can see in the book [108]; there anybody can find the Theory for understanding the errors, as given in the document [116] Galetto, F., 2017, Imperfect-age-maintenance_WRONG paper found in Academia.edu, Published in the Academia.edu.

Any scholar, researcher, student must follow the concepts in the figures 26 and 27, IF they want to act with Quality...

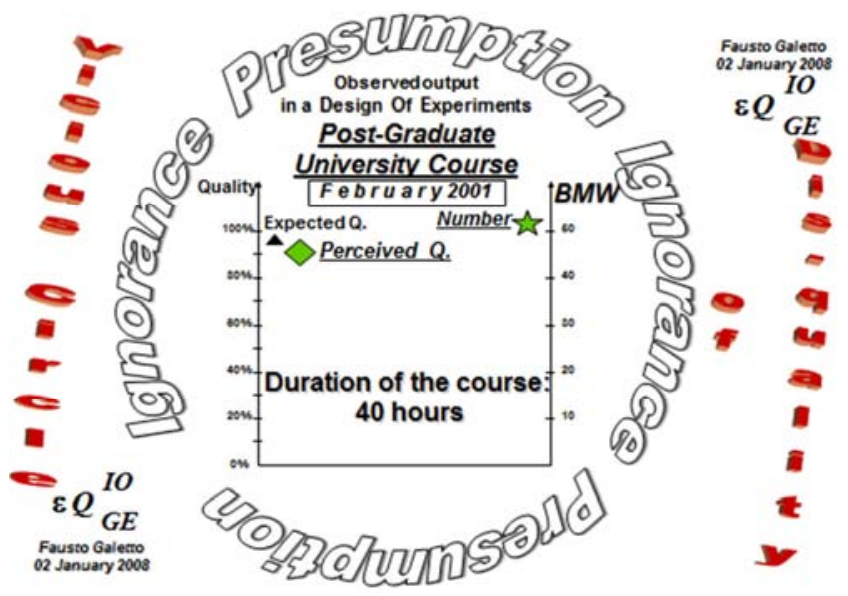

Figure 27. The Disquality Vicious Circle.
Any scholar, researcher, student must consider that, IF they want to act with Quality, the Knowledge-Making process and the Knowledge itself need to have Quality got through Quality Tools and Methods as it is depicted in the figure 28, Quality Tools and Quality Methods to avoid the Disquality.

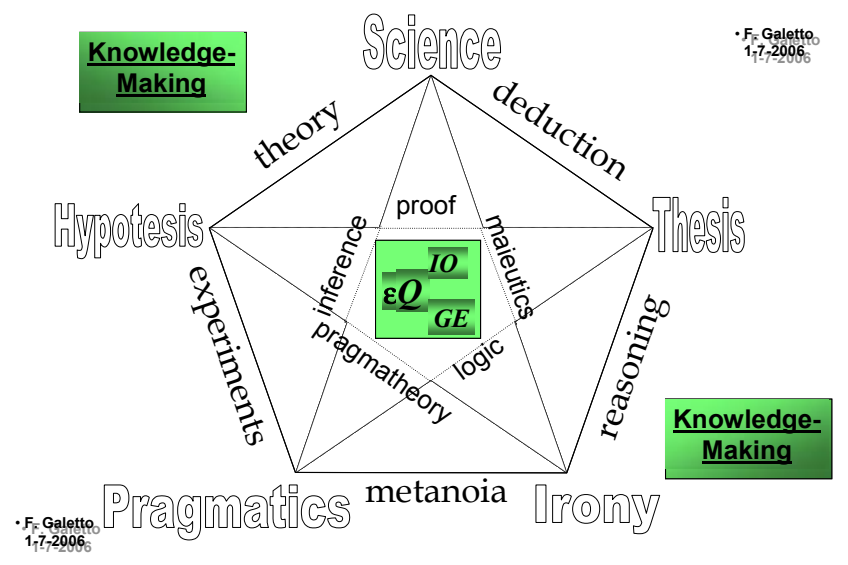

Figure 28. Quality Tools and Quality Methods to avoid the Disquality.

Unfortunately too many researchers think that citations of papers and books are an index of the Quality of the methods given in those papers and books: according to the author this is a very BAD attitude. On the contrary they should use the correct (Scientific) way to analyse the data and make decisions about the methods suggested.

Compare the F. Galetto findings opposite to what is found in the web where Open Access Journals are criticized because they are "means for tricking people" (asking fees for publishing papers). For example, for Science Publishing Group, they say either [1] "Science Publishing Group is another scam Open Access journal publisher or academic vanity press.... the journals put out by the Science Publishing Group are not read by scientists and have no impact factor." or [2] "They will distribute it globally and pretend it is real research, for a fee. It's untrue? And parts are plagiarized? They're fine with that. Welcome to the world of science scams, a fast-growing business that sucks money out of research, undermines genuine scientific knowledge, and provides fake credentials for the desperate."

It is very clear, to any sensible student, that the bad quality of the papers published do not depend on the fee, asked by the Open Access Publishers (OAP), but on the very low quality of the authors and of the Peer Reviewers; the same happens for "well reputed magazines and journals" published by Non_Open Access Publishers (NOAP) [from 85 to 95, 115].

\section{Conclusion (Using SPQR)}

We showed that, using Logic, Science and the SPQR Principle, we can understand if a "proposed method" is to be used or it must be refused.

The author thinks that this is very important for any student, researcher and scholar, especially if they look at figure 1.

The author, as lecturer of Quality Management (at Politecnico of Turin, Italy), always invited the student and 
professors to use Logic, Science and the SPQR Principle, as the reader can see form the following case.

While attending (as an "intelligent pupil") a Post-Graduate University course on DOE (2001), provided by "Montgomery fans" (someone of QEG was teaching there) Fausto Galetto had the opportunity to experience the incapability of teaching "scientifically" the matter they were dealing; at that time Fausto Galetto invented the Disquality Vicious Circle "Presumption-Ignorance-Presumption-Ignorance" because the lecturers were unable to teach "scientifically"... (Figure 27, published on 2008).

The author for many years, with papers in many Conferences [34-101, 111], and with books [102-110], tried to diffuse the idea that decision-making has to be based on Scientific Methods. See also [112, 113] in Academia.edu and Research Gate.

He thinks that the readers (Professors, Managers, Researchers, Scholars) must stay with STEM (Science, Technology, Engineering and Mathematics), i.e. LOGIC to prevent and avoid DISquality! (see the Quality Tetralogy)

IF the scholars want to make Quality (of papers, of books, of teaching) they must remember Figure 26 (FAUSTA GRATIA for Quality in order to avoid the Disquality) and Figure 27 (The Disquality Vicious Circle).

Since "Quality of Methods for Quality is important" [50] and there are methods misleading (e.g. Taguchi Methods, Bayes Methods,...) it is better that MANAGERS, STUDENTS RESEARCHERS, PROFESSORS, SHOLARS BE EDUCATED ON QUALITY, always thinking to Deming statements from his very good book Out of Crisis.

a) Experience alone, without theory, teaches management nothing about what to do to improve quality and competitive position, nor how to do it. (pag. 19)

b) It is a hazard to copy. It is necessary to understand the theory of what one wishes to do or to make. (pag. 129)

c) The result is that hundreds of people are learning what is wrong. (pag. 131)

d) I make this statement on the basis of experience, seeing every day the devastating effects of incompetent teaching and faulty applications. (pag. 131)

To be in line with figure $1,26,27$, there are two fundamental principles to use fully the thinking ability of people:

F1 Reality does exist in spite of human beings' willingness and ability to recognize it.

F2 Variation is in everything and everywhere, all the time.

From F1 any scholar must not hide the information about the truth present in the data...

From F2 we derive that "variation" is NOT the enemy of Quality», as several "intelligent (are they ????)" people say! Variation is in every phenomenon and is important: if life was developing for millions of years that was merit of the VARIATION! The sons of relatives have more problems than the sons of NON_relatives... Biodiversity is the foundation of ecosystems to which human well-being is intimately linked.

Every "author's opinion" is based on this long experience in the Quality Field: they are not only opinions, they are hard facts. See the figures and the papers: Fausto Galetto during the "students' defence of their final thesis" (to get their degree in Engineering) used to open the written thesis at a "random" page and to ask the future graduate what he meant with some statements found in there. $90 \%-98 \%$ of the students did not know how to provide any answer to the questions: moreover, $50 \%-60 \%$ said "I copied it from the web!" That was not the biggest problem: it always astonished me the fact that the (Professor) Referee of the thesis did not know the matter/answer himself! These are hard facts, not opinion; the same were for Deming and Gell-Mann..., and Einstein...

SPQR was used by Galileo Galilei and by the great scientist Isaac Newton when he said "If I have seen farther than others, it is because I have stood on the shoulders of giants"; the process of Science is such that the discoveries of one people generation serve for the next one, by knowledge accumulation. This is true for any discipline (e.g. Logic, Mathematics, Physics, Probability, Statistics, Medicine, Economics, Reliability...): any building needs sound foundations [fundamental principles F1 and F2].

When using other people words (like those of Newton, Galilei, Einstein, Deming, Gell-Mann...) the Fausto Galetto tries to show that very great scholars have been providing correct hints to the readers in order to help them increasing their knowledge...

The Knowledge-Making process and the Knowledge itself must have Quality got through Quality Tools and Methods; this is depicted in the figure 28, Quality Tools and Quality Methods to avoid the Disquality.

Figures 26, 27, 28 were completely disregarded by QEG when they, based on an idea by Kosmulski, who (2011) proposed to classify a paper as "successful" when receiving more citations than those made; they decided (in their paper "An informetric model for the success-index" appeared on Scientometrics, 2012) to propose to classify a publication as "successful" when it receives more citations than a specific comparison term $(C T)$. In the intention of the QEG authors $C T$ should be a suitable estimate of the number of citations that a publication - in a certain scientific context and period of time - should potentially achieve. According to this definition, the success-index is defined as the number of successful papers, among a group of publications examined, such as those associated to a scientist or a journal. QEG gave particular emphasis to a theoretical sensitivity analysis of the success-index (s-index).

The F. Galetto paper [97] shows the many drawbacks of this QEG attitude. [again QEG!, as we saw before]

This shows that the Open Access Publishers are not the problem: the problems are generated by incompetent authors even though when they go to "good (so called!) publishers"...

Other cases are found in Research Gate documents.

Any sensible Scholar must take into account that the Scientific Attitude provides good results, using the SPQR Principle.

Doing that any serious scholar can see the drawbacks both of Open Access Publishers (OAP) and Non-Open Access Publishers (NOAP): the bad quality of the paper published does not depend on the fee, asked by the OA Publishers (OAP), 
but on the very low quality of the authors and of the Peer Reviewers; the same happens for "well reputed magazines and journals" (NOAP).

We saw that several NOAP Journal published papers of the Quality Engineering Group (QEG, comprising several professors suggesting the Montgomery books to students; therefore it is not a surprise that the case we analyse here has various problems [11, 12]). QEG advertises: ««Welcome to the website of the Quality Engineering Group.... The research group... deals with research areas related to Quality Engineering. In particular current research interests are in the areas of Statistical Process Control, Service Quality Management and Industrial Metrology. The group is working also on Bibliometrics and Performance Indicators. This website was created with the goal of promoting the research activities carried out by the group. ॥। Fantastic... See Ref.

The readers have to remember Deming, Juran, Gell-Mann, Shewhart [3-8] and A. Einstein who wrote: «An Academic career poses a person in an embarrassing position, asking him to produce a great number of scientific publications; only strong personalities can resist to this seduction toward the superficiality... I am very grateful to Marcel Grossmann if I had the fortune not to be in this hard position.» It is not surprising that professors, researcher, managers, scholars and students learn wrong ideas, in the Quality field, BECAUSE we have a very widespread book with many wrong concepts \{e.g., D. C. Montgomery falls in contradiction! He spreads wrong concept on Quality $[9,10]\}$. Is Wiley \& Sons an OAP? Surely it is not!

\section{References}

[1] scienceblogs.com/.../2012/.../nice-try-science-publishing-group

[2] www.sabhlokcity.com/.../more-on-the-science-publishing-gro up...

[3] Deming W. E., 1986, Out of the Crisis, Cambridge University Press.

[4] Deming W. E., 1997, The new economics for industry, government, education, Cambridge University Press.

[5] Juran, J., 1988, Quality Control Handbook, 4th ed, McGraw-Hill, New York.

[6] M. Gell-Mann., 1994, The Quark and the Jaguar: Adventures in the Simple and the Complex, W. Freeman and Company, N. Y.

[7] Shewhart W. A., 1931, Economic Control of Quality of Manufactured Products, D. Van Nostrand Company.

[8] Shewhart W. A., 1936, Statistical Method from the Viewpoint of Quality Control, Graduate School, Washington.

[9] Montgomery D. C., 1996, Introduction to Statistical Quality Control, Wiley \& Sons (wrong definition of the term "Quality", and many other drawbacks in wrong applications).

[10] Montgomery D. C., 2009, $6^{\text {th }}$ edition, Introduction to Statistical Quality Control, Wiley \& Sons (wrong).

[11] Montgomery D. C., 2011, $5^{\text {th }}$ edition, Applied Statistics And Probability For Engineers, Wiley \& Sons.
[12] Montgomery D. C., 2013, $8^{\text {th }}$ edition, Design and Analysis of Experiments, Wiley \& Sons.

[13] Montgomery D. C., editions after 2009 are worse, Introduction to Statistical Quality Control, Wiley \& Sons (wrong definition of the term "Quality", and many other drawbacks in wrong applications).

[14] Cascini E., Sei Sigma per docenti in 14 capitoli, RCE Multimedia 2009.

[15] Arcidiacono G., et al. Governare i processi per governare l'impresa - Lean Six Sigma, Springer 2014.

[16] Citti P., La metodologia sei sigma nei servizi, Firenze University Press 2006.

[17] Pyzdek T., The Six Sigma Handbook A Complete Guide For Green Belts, Black Belts, And Managers At All Levels, McGraw-Hill 2003.

[18] Munro R., et al., The Certified Six Sigma Green Belt Handbook, American Society for Quality 2015.

[19] Pande P., et al., The Six Sigma Way_How GE, Motorola, and Other Top Companies are Honing their performance, McGraw-Hill.

[20] Brue G., Six Sigma for Managers, McGraw-Hill 2005.

[21] Eckes G., Six Sigma for Everyone- (2003) Managers, Wiley 2003.

[22] Craig G. et al., Six Sigma for Dummies, Wiley 2012.

[23] Allen T., Introduction to Engineering Statistics and Six Sigma, Springer 2006.

[24] PARK S. (1996), Robust Design and Analysis for Quality Engineering, Chapman \& Hall, London.

[25] F. Kutsanedzie, S. Achio, E. Ameko, Basic concepts and applications of experimental design, Science Publishing Group 2015, ISBN: 978-1-940366-500.

[26] Taguchi G., "Product quality evaluation and tolerancing", 30th EOQC Conference, Stockholm 1986.

[27] Taguchi G., System of Experimental Design, vol. 1, ASI (American Supplier Institute) and Unipub Kraus International Publications.

[28] Taguchi G., System of Experimental Design, vol. 2, ASI and Unipub Kraus International Publications.

[29] Taguchi G., Introduction to quality engineering, Asian Productivity Organization, 1988.

[30] Taguchi G., Yu-In Wu, Introduction to off-line quality control, Central Japan Quality Control Association, 1979.

[31] Taguchi S., Byrne D., 1986 The Taguchi Approach to Parameter Design, Best Technical Paper (!?), American Society for Quality Control.

[32] F. Franceschini, M. Galetto, D. Maisano, L. Mastrogiacomo, B. Pralio, Distributed Large-Scale Dimensional Metrology, New Insights, Springer-Verlag London Limited 2011.

[33] Franceschini F, Maisano D, Mastrogiacomo L, Pralio B (2010) Ultrasound transducers for largescale metrology: a performance analysis for their use by the MScMS. IEEE Trans Instrum Meas 59 (1): 110-121. 
[34] F. Galetto, Nuovi sviluppi nel calcolo dei parametri affidabilistici dei sistemi, LXXIII Riunione annuale AEI, Torino, 1972.

[35] F. Galetto, Numero dei guasti di un sistema e determinazione di un modello reale atto a rappresentarlo, VIII congr. AICQ, Napoli, 1973.

[36] F. Galetto, Integrazione Numerica di Equazioni Integrali di Volterra, Facoltà di Matematica, Bologna, 1973.

[37] F. Galetto, Pitfalls of Bayes Methods, Internat. conf. on Reliability/ Diagnostics, Torino, 1986.

[38] F. Galetto, CLARA (Cost and Life Appraisal via Reliability Analysis), $30^{\text {th }}$ EOQC Conference, Stoccolma, 1986.

[39] F. Galetto, SARA (System Availability and Reliability Analysis), Annual Reliability Symposium, Philadelphia, 1977.

[40] F. Galetto, CLAUDIA (Cost and Life Analysis via Up and Down time Integral Approach), XXI EOQC Conf., Varna, 1977.

[41] GALETTO F. (1978), An application of experimental design in the Automotive field, SIA Congress.

[42] F. Galetto, NORA (a New Outlook on Reliability of Automobiles), XXIII EOQC Conf., Budapest, 1979.

[43] F. Galetto, New results in reliability analysis, $2^{\text {nd }}$ Int. Conf. on Reliability/ Maintainab., Perros- Guirec, 1980.

[44] GALETTO F. (1984) Assessment of Product Reliability, World Quality Congress '84, Brighton.

[45] GALETTO F. (1986) Quality/Reliability: How to get results, EOQC (Automotive Section), Madrid.

[46] F. Galetto, Are Bayes Methods really better ?, IASTED Int. Conf. on Quality/ Reliability, Paris, 1987.

[47] GALETTO F. (1987) Quality and Reliability, the Iveco way, Mgt Dev. Review by MCE, Brussels.

[48] GALETTO F. (1988) Quality and reliability. A must for industry, ISATA, Montecarlo.

[49] F. Galetto, Comment on: 'New Practical Bayes Estimators for the 2-parameters Weibull distribution, IEEE Transactions on Reliability vol. 37, 1988.

[50] GALETTO F. (1989) Quality of methods for quality is important, EOQC Conference, Vienna.

[51] GALETTO F. (1990) Basic and managerial concerns on Taguchi Methods, ISATA, Florence.

[52] F. Galetto, Qualità. Alcuni metodi statistici da Manager, CUSL, 1995.

[53] F. Galetto, Quality: Management Commitment is not enough, ISATA, Vienna, 1990.

[54] GALETTO F., LEVI R. (1993) Planned Experiments: key factors for product Quality, 3rd AMST 93, Udine.

[55] GALETTO F. (1993) DOE. Importanti idee sulla Qualità per i manager, DEINDE, Torino.

[56] GALETTO F. (1993) Which kind of Quality? Of products, of processes, of Management? $1^{\text {st }}$ AITEM, Ancona.

[57] Galetto, F., Managerial Issues for Design of Experiments, $4^{\text {th }}$
AMST 96, Udine, 1996.

[58] Galetto, F., We need Quality of Managers, Quality 97, $6^{\text {th }}$ Intern. Conf., Ostrava, Czeh Republic, 1997.

[59] Galetto, F., Quality Education on Quality for Future Managers, $I^{\text {st }}$ Conference on TQM for HEI (Higher Education Institutions), Tolone, 1998.

[60] Galetto, F., GIQA the Golden Integral Quality Approach: from Management of Quality to Quality of Management, Total Quality Management (TQM), Vol. 10, No. 1, 1999.

[61] Galetto, F., Quality Education and Total Quality Management, $2^{\text {nd }}$ Conf. on TQM for HEI, Verona, 1999.

[62] Galetto, F., Quality Methods for Design of Experiments, $5^{\text {th }}$ AMST 99, Udine, 1999.

[63] Galetto, F., Quality Function Deployment, Some Managerial Concerns, AITEM99, Brescia, 1999.

[64] GALETTO F., GENTILI E. (1999), The need of Quality Methods used for Quality CAPE '99, Durham, UK.

[65] GALETTO F., GENTILI E. (1999), Quality of the Quality Methods, AITEM 99 Conference, Brescia.

[66] GALETTO F., GENTILI E. (2000), In search of Quality in QFD and Taguchi methods, CAPE.

[67] GALETTO F. (2000) Qualità. Alcuni metodi statistici da Manager, CLUT, Torino.

[68] Galetto, F., Quality Education for Professors teaching Quality to Future Managers, $3^{\text {rd }}$ Conf. on TQM for HEI, Derby, UK, 2000.

[69] Galetto, F., Statistical Thinking, Customer Satisfaction, Qualità del Servizio e Formazione Universitaria, Conv. SIS, Firenze, 2000 .

[70] Galetto, F., Quality, Bayes Methods and Control Charts, $2^{\text {nd }}$ ICME 2000 Conference, Capri, 2000.

[71] Galetto, F., Reliability Integral Theory applied to "two machines lines" with failures, $2^{\text {nd }}$ ICME 2000 Conference, Capri, 2000.

[72] Galetto, F., RELIABILITY PREDICTION DURING DEVELOPMENT, ATA conf., Firenze, 2000.

[73] Galetto, F., Looking for Quality in "quality books", $4^{\text {th }}$ Conf. on TQM for HEI, Mons, Belgium, 2001.

[74] Galetto, F., Quality and Control Carts: Managerial assessment during Product Development and Production Process, AT\&T (Society of Automotive Engineers), Barcelona, 2001.

[75] Galetto, F., Quality QFD and control charts: a managerial assessment during the product development process, Congresso ATA, Firenze, 2001.

[76] Galetto, F., Business excellence Quality and Control Charts, $7^{\text {th }}$ TQM Conf., Verona, 2002.

[77] Galetto, F., Fuzzy Logic and Control Charts, $3^{\text {rd }}$ ICME 2002 Conference, Ischia, 2002.

[78] Galetto, F., Quality education on Quality for future managers, 5th World Congr. on Engineering Education of NOT, Varsavia, 2002.

[79] Galetto, F., Analysis of "new" control charts for Quality assessment, $5^{\text {th }}$ Conf. on TQM for HEI, Lisbon, Portugal, 2002. 
[80] Galetto, F., Quality decisions and ISO 9000:2000 Principles, 6th AMST 99, Udine, 2002.

[81] Galetto, F., Quality and “quality magazines", $6{ }^{\text {th }}$ Conf. on TQM for HEI, Oviedo, Spain, 2003.

[82] Galetto F., G. Pistone, M. P. Rogantin, Confounding revisited with commutative computational algebra, Journal of statistical planning and inference,, 2003.

[83] Galetto, F., "Six Sigma Approach" and Testing, ICEM12 -12 $2^{\text {th }}$ Intern. Conf. on Experimental Mechanics, Bari Politecnico, 2004.

[84] Galetto, F., Reliability analysis in product development, AMST 2005, Udine, 2005.

[85] Galetto, F., Statistics for Quality and "quality magazines", $5^{\text {th }}$ ENBIS, Newcastle, 2005.

[86] Galetto, F., Service Quality: Fuzzy Logic and Yager Method; a scientific analysis, IFIP TC 7, Politecnico di Torino, 2005.

[87] Galetto, F., Quality and "Statistics Packages", $8^{\text {th }}$ Conf. on TQM for HEI, Palermo, 2005.

[88] Galetto, F., Quality Education and “quality papers", IPSI 2006, Marbella, 2006.

[89] Galetto, F., Fuzzy Logic and Quality Control: a scientific analysis, IPSI 2006, Amalfi, 2006.

[90] Galetto, F., Quality Education versus "Peer Review", IPSI 2006 , Montenegro, 2006.

[91] Galetto, F., Does "Peer Review" assure Quality of papers and Education?, $8^{\text {th }}$ Conf. on TQM for HEI, Paisley, Scotland, 2006.

[92] Galetto, F., Quality Education versus "Peer Review", IPSI 2006, Montenegro, 2006.

[93] Galetto, F., A must: Quality of teaching, IPSI 2006, Portofino, 2006.

[94] Galetto, F., The Pentalogy, VIPSI, Belgrado, 2009.

[95] Galetto, F., The Pentalogy Beyond, $9^{\text {th }}$ Conf. on TQM for HEI, Verona, 2010.

[96] Galetto, F., Six Sigma: help or hoax for Quality?, $11^{\text {th }}$ Conf. on TQM for HEI, Israel, 2012.

[97] Galetto, F., Bibliometrics: Help or Hoax for Quality?, UJER 2 (4), DOI: 10.13189/ujer.2014.020404, 2014.

[98] Galetto, F., Riemann Hypothesis Proved, Academia Arena 6 (12): 19-22, ISSN 1553-992X, 2014.

[99] Galetto, F., Hope for the Future: Overcoming the DEEP Ignorance on the CI (Confidence Intervals) and on the DOE (Design of Experiments, Science J. Applied Mathematics and Statistics. Vol. 3, No. 3, pp. 70-95, doi: 10.11648/j.sjams.20150303.12, 2015.

[100] Galetto, F., Management Versus Science: Peer-Reviewers do not Know the Subject They Have to Analyse, Journal of Investment and Management. Vol. 4, No. 6, pp. 319-329, doi: 10.11648/j.jim.20150406.15, 2015.

[101] Galetto, F., The first step to Science Innovation: Down to the Basics., Journal of Investment and Management. Vol. 4, No. 6, pp. 319-329, doi: 10.11648/j.jim.20150406.15, 2015.
[102] Galetto, F., AFFIDABILITÀ vol. 1 Teoria e Metodi di calcolo, CLEUP editore, Padova, 81, 84, 87, 94.

[103] Galetto, F., AFFIDABILITÀ vol. 2 Prove di affidabilità: distribuzione incognita, distribuzione esponenziale, CLEUP editore, Padova, 82, 85, 94.

[104] Galetto, F., Qualità. Alcuni metodi statistici da Manager, CUSL, 1995/7/9.

[105] Galetto, F., Gestione Manageriale della Affidabilità. CLUT, Torino.

[106] Galetto, F., Manutenzione e Affidabilità. CLUT, Torino.

[107] Galetto, F., 2016, Reliability and Maintenance, Scientific Methods, Practical Approach, Vol-1, www.morebooks.de.

[108] Galetto, F., 2016, Reliability and Maintenance, Scientific Methods, Practical Approach, Vol-2, www.morebooks.de.

[109] Galetto, F., 2016, Design Of Experiments and Decisions, Scientific Methods, Practscal Approach, www.morebooks.de.

[110] Galetto, F., 2017, The Six Sigma HOAX versus the versus the Golden Integral Quality Approach LEGACY, www.morebooks.de.

[111] Galetto, F., 2017, Six Sigma Hoax: The Way Professionals Deceive Science. Nuclear Science. Vol. 2, No. 3, 2017, pp. 59-81. doi: 10.11648/j.ns.20170203.11

[112] Galetto, F., Papers and Documents in the Academia.edu, 2015-2017.

[113] Galetto, F., Several Papers and Documents in the Research Gate Database, 2014.

[114] S El-Ferik and M Ben-Daya, 2008, Model for imperfect age-based preventive maintenance with age reduction, Journal of the Operational Research Society (2008) 59, $1644-1651$.

[115] Galetto, F., 2017, Imperfect-age-maintenance_WRONG paper found in Academia.edu, Published in the Academia.edu.

\section{Biography}

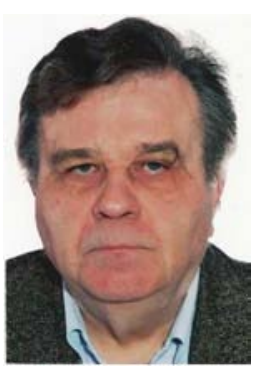

Fausto Galetto (born Italy 1942) Electronics Engineering and Mathematics degrees (Bologna University, 1967, 1973). 1992-2012 Professor of "Industrial Quality Management" at Politecnico of Turin.

1998-2001 Chairman of the Committee "AICQ-Università" (Quality in Courses about Quality in Universities).

Eight books, 200 papers on Reliability, Quality (Management, DOE, Statistics, Testing, Process Control).

Reliability Engineer (General Electric, 2 years), 1975-1982 Reliability Manager (Fiat Auto, now FCA); Quality Director (Philco 3 years). 1985-1990 Quality/Reliability Director (Iveco). Since 1990 Quality Management consultant. Lecturer with AICQ/COREP (1980-2012). He is one of the very few who take care of "Quality of Quality Methods used for making Quality". 